\title{
MORTALITY FROM EXTERNAL CAUSES IN RUSSIA OVER HALF A CENTURY*
}

\author{
EKATERINA KVASHA, TATYANA KHARKOVA, VALERIY YUMAGUZIN
}

\begin{abstract}
The article discusses long-term mortality trends (since 1956) from external causes of death in Russia. Russia has long lagged behind developed countries in this domain. The level of mortality from external causes of death remains high and its structure is still archaic with large contribution of homicides, alcohol poisoning and injuries of undetermined intent.
\end{abstract}

Excess number of deaths from life tables of Russia and Western European countries is compared. It is shown that in Russia the greatest excess losses are associated with mortality from poisonings among both sexes, suicide among men and homicide among women.

Mortality from external causes, along with mortality from diseases of the circulatory system, has had a significant impact on life expectancy. In general, over the period 1956-2012 the increase in mortality from external causes in the 15-64 age group reduced life expectancy by 2.6 years for males and 0.7 years for females.

The decline, starting in 2003, of mortality from external causes of death has slightly reduced the gap between Russia and developed countries, bringing the current Russian level closer to those levels reached in Russia in the mid-1960s and 1980s. However, given the fluctuations of mortality from external causes, it is premature to say whether the current decline in mortality is robust.

Key words: mortality in Russia, external causes of death, excess mortality, life expectancy.

\section{MORTALITY FROM EXTERNAL CAUSES AGAINST THE BACKGROUND OF OVERALL MORTALITY}

Regular statistics of mortality from external causes in Russia have been kept since 1956 [Bogoyavlensky 2001]. They became available to researchers in the early 1990s, but then their use was hampered by the violation of the comparability of continuous time series when changing from one revision of the International Classification of Causes of Death to another. For years, a group of French and Russian demographers worked painstakingly on the reclassification of data from one nomenclature of causes of death to the other, in order to ensure the comparability of the continuous series of data.

EKATERINA KVASHA. InStitute of DEMography, NATIONAL RESEARCh UNIVERSITy Higher SchoOl of ECONOMICS. E-MAIL: ekvasha@hse.ru.

TATIANA KHARKOVA. Institute of Demography, National RESEARCH University Higher SchoOl OF ECONOMICS. E-MAIL: tkharkova@hse.ru.

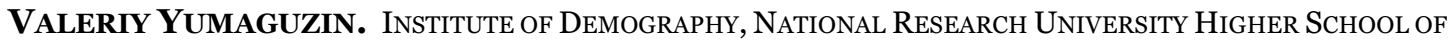
ECONOMICS. E-MAIL: vyumaguzin@hse.ru.

TRANSLATED FROM: ДЕМОГРАФИЧЕСКОЕ ОБОЗРЕНИЕ. 2014, 1(4): 68-95. ORIGINAL TITLE: “СМЕРTHOCTЬ ОT ВНЕШНИХ ПРИЧИН в РОССИИ ЗА ПОЛВЕКА” (НТТР://DEMREVIEW.HSE.RU/EN/2014--4/150230215.HTML).

\footnotetext{
* THIS STUDY WAS IMPLEMENTED UNDER “THE NATIONAL RESEARCH UNIVERSITY HIGHER SCHOOL OF ECONOMICS ACADEMIC FUND" PROGRAM, RESEARCH GRANT № O5-OO29 “EXTERNAL CAUSES OF DEATH IN THE SYSTEM OF PRIORITIES IN THE FIGHT FOR THE LIFE EXPECTANCY INCREASE IN RUSSIA”.
} 
The first results of this work on Russia were published in 1996 and relate to the period 1965-1994 [Meslé et al. 1996]. The time series includes 175 comparable causes of death as coded in the Soviet nomenclature in use since 1988. A few years later, the same group of authors, joined by E.M. Andreev, continued the work [Meslé et al. 2003], and constructed a continuous series of data beginning in 1959 [RosBRiS 2014]. As a complement to official Rosstat data for the years 1956-1958 and from the late 1990s, these data provide a reliable basis for the analysis of mortality from external causes for a period of more than half a century. The following analysis is largely based on these data.

Using previously unpublished or archived data on the pre-revolutionary period, D.D. Bogoyavlensky reconstructed a continuous time series of indicators of deaths from violence in 1870-1914 for 50 provinces of European Russia. Combining these data with those for all of Russia since 1956 shows, notwithstanding incomplete geographical overlap, the dynamics of mortality from external causes in Russia for nearly half a century (Figure 1).

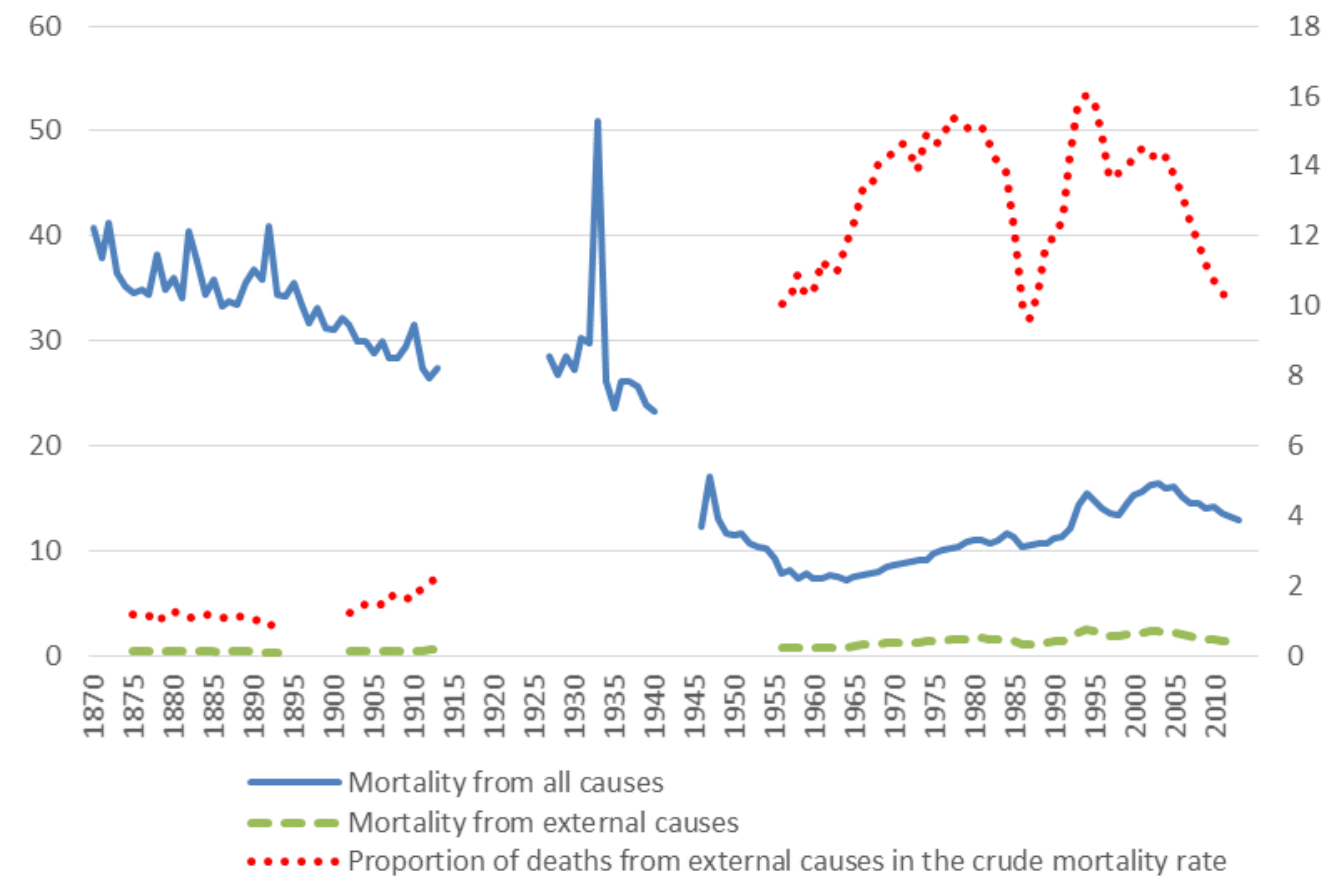

Figure 1. Crude death rate from all causes of death and from external causes (deaths per 1000) and the proportion of deaths from external causes in the crude mortality rate (right scale, percent), 50 European provinces of the Russian Empire and the Russian Federation, 1870-2012

Source: Calculated from [Bogoyavlensky 2001; Rosstat 2013].

Commenting on his graph, D.D. Bogoyavlensky draws attention to the constantly growing role of mortality from external causes. "While the crude mortality rate in Russia declined gradually and intermittently over a hundred years, the mortality rate from external causes grew continuously, and this growth continued when the crude mortality rate began to rise. Moreover, it is precisely the growth of violent deaths which made a very large contribution to the overall increase in mortality in Russia in the last third of the twentieth century" [Bogoyavlensky 2001]. 
Over the entire period from 1956 to 2013 , for which there are continuous data, 12.1 million people died from this class of causes in Russia (or more than 13\% of all deaths). From 1956 to the mid-1980s the number of deaths from external causes grew steadily, then went down for a short time during Perestroika (i.e. the anti-alcohol campaign) and then again resumed growth, reaching a historic high in 1994 (Figure 2).

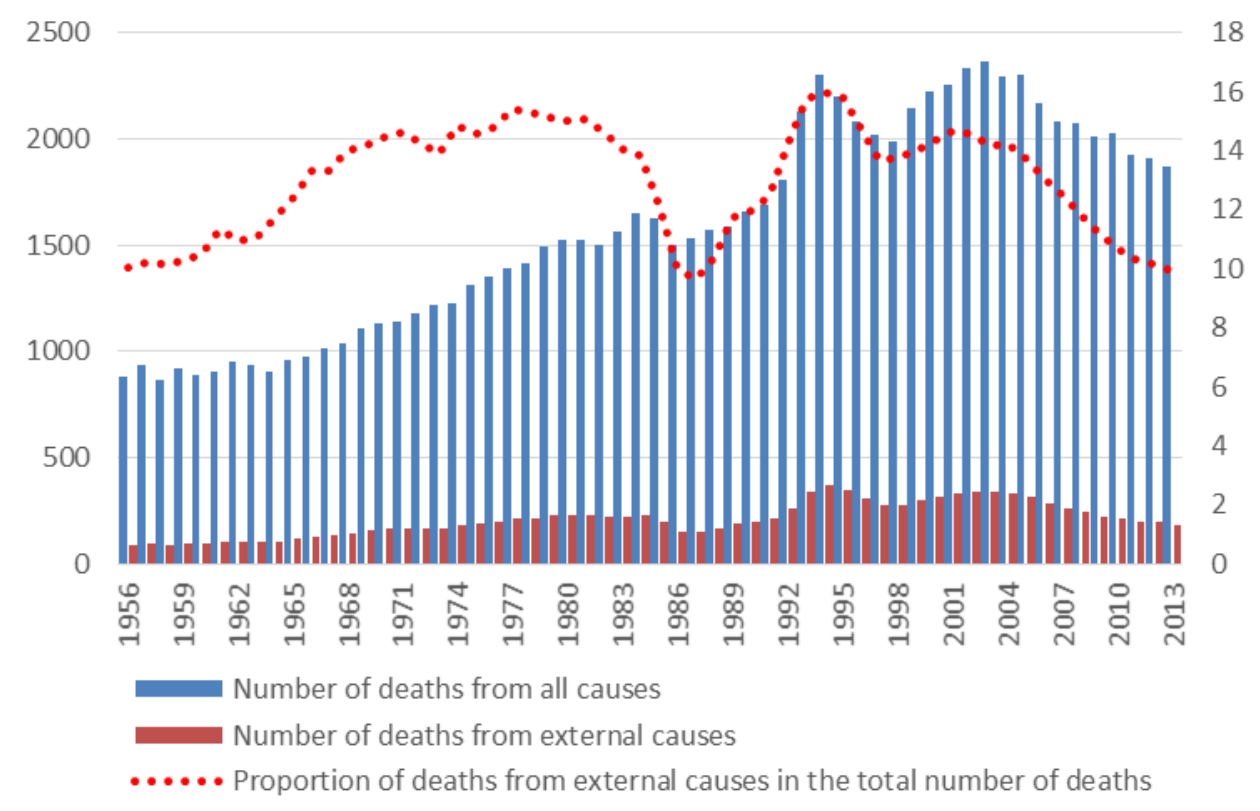

Figure 2: Number of deaths from all causes and from external causes (bars, left scale, thousands) and the proportion of deaths from external causes in the total number of deaths (line, right scale, percent), Russia, 1956-2013

Source: Calculated from [RosBRiS 2014].

This hike was followed by a short-lived decrease and after 1998, a new rise which peaked in 2003. Since then, the decline has continued with small fluctuations until now. In 2011, the number of deaths from external causes fell below 200,000 for the first time since 1990, and in 2012 - below the level of 1998 .

As shown on Figure 2, the reduction in the number of deaths from external causes is accompanied by the decrease of their share in the total number of deaths. Yet it remains very high. In a country where the contribution of external factors to the overall mortality was once $1-2 \%$, after 1956 it fell several times, declining close to $10 \%$ in the best of years, but often jumping upwards of $15 \%$. After peaking in 1994, when the proportion of deaths from external causes reached a maximum (16\%), it fell to $10.2 \%$ in 2012 and to $9.9 \%$ in 2013 . However, in most European countries this share is much lower (Figure 3). In the United States, a country with a population 2.2 times larger than in Russia, in 2012 external causes claimed 190 thousand lives [NCHS 2014] versus 194 thousand in Russia. 


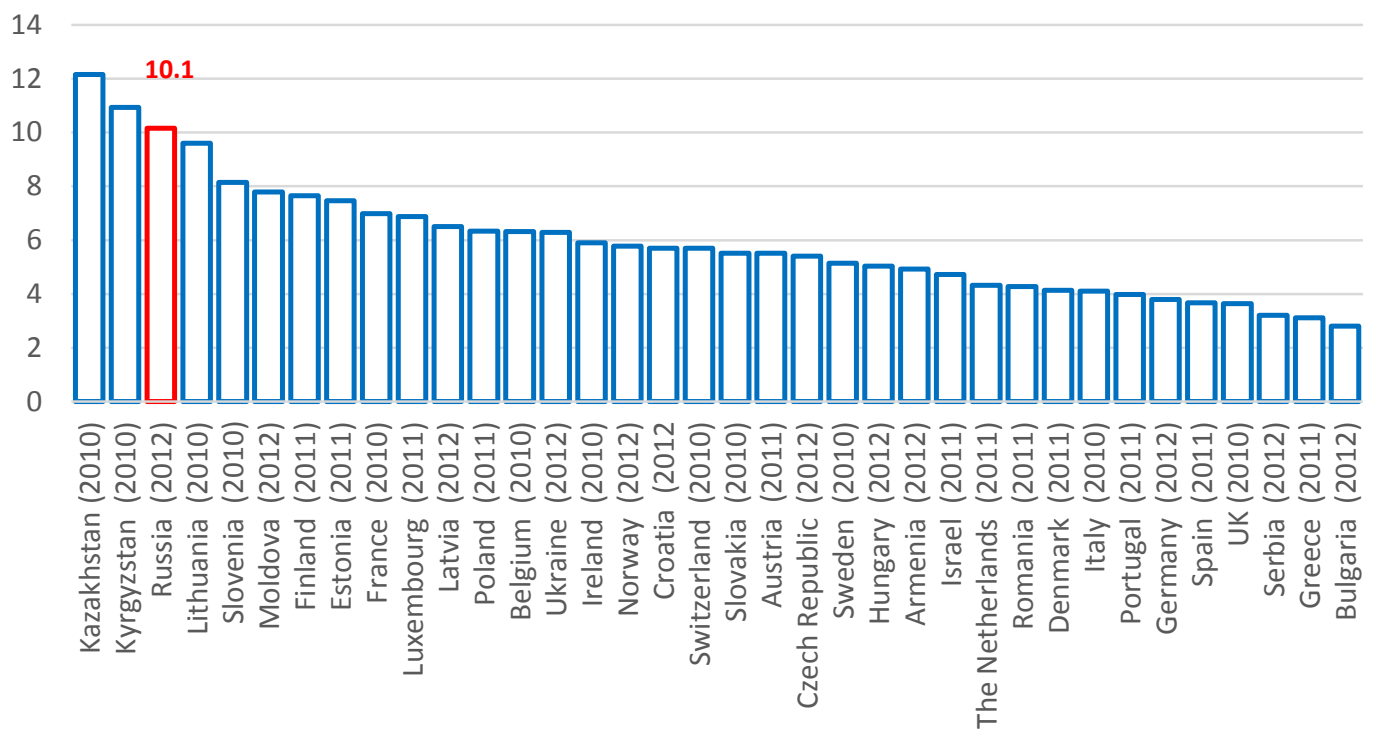

Figure 3. Proportion of deaths from external causes in the total number of deaths in Russia and some countries of the world, 2010-2012, \%

Source: Calculated from [Rosstat 2013; WHO DMDB 2014].

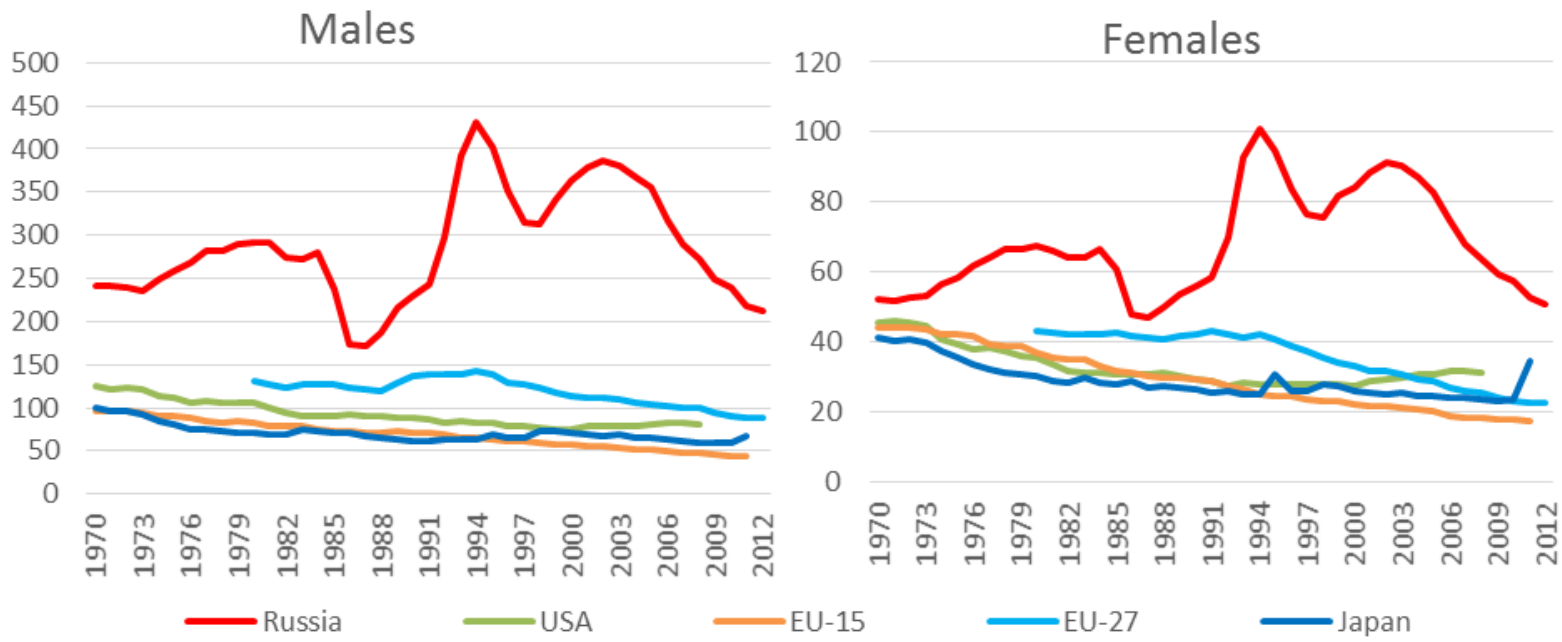

Figure 4. Standardized mortality rate from external causes in Russia, the average for the European Union (EU-15 ${ }^{1}$ and EU-27²), the United States and Japan, by sex, 1970-2012, per 100 thousand persons

Note: WHO European standard is used for computations.

Source: Calculated from [Rosstat 2013, WHO MDB 2014; WHO HFA 2014].

Russia's huge gap with other developed countries is also seen in the standardized rate of mortality from external causes. Even in the early 1970s, when the gap was narrower than it is now, this coefficient for men in Russia was two to three times higher than in the West, with a somewhat

\footnotetext{
1 Austria, Belgium, Denmark, Finland, France, Germany, Greece, Ireland, Italy, Luxemburg, the Netherlands, Portugal, Spain, Sweden and the United Kingdom.

${ }^{2}$ Countries listed in footnote 1 plus Bulgaria, Czech Republic, Cyprus, Estonia, Hungary, Latvia, Lithuania, Malta, Poland, Romania, Slovakia and Slovenia.
} 
smaller, but significant, excess for women. Further reduction of mortality from external causes in Western countries and its concurrent growth in Russia sharply increased the gap: in some years, this coefficient surpassed the typical Western levels for men by the factor of 7 or even 8 , and for women by the factors of 4 or 5 . In recent years, there has been some convergence, but very large differences persist (Figure 4).

Similarly to the absolute number of deaths, the standardized rate of mortality from external causes has been declining recently, but up to now it only restored the level of the early 1990s, which also was very high. Moreover, the gap between Russia and some other developed countries is even increasing. The contribution of deaths from external causes to the standardized mortality rate is very large. Although in some European countries with overall mortality below Russia's level the contribution of external causes of death is similar to Russia's, these countries are few. On average, this contribution is twice as high in Russia as in the European Union (either EU-15 or EU-25) (Figure 5).

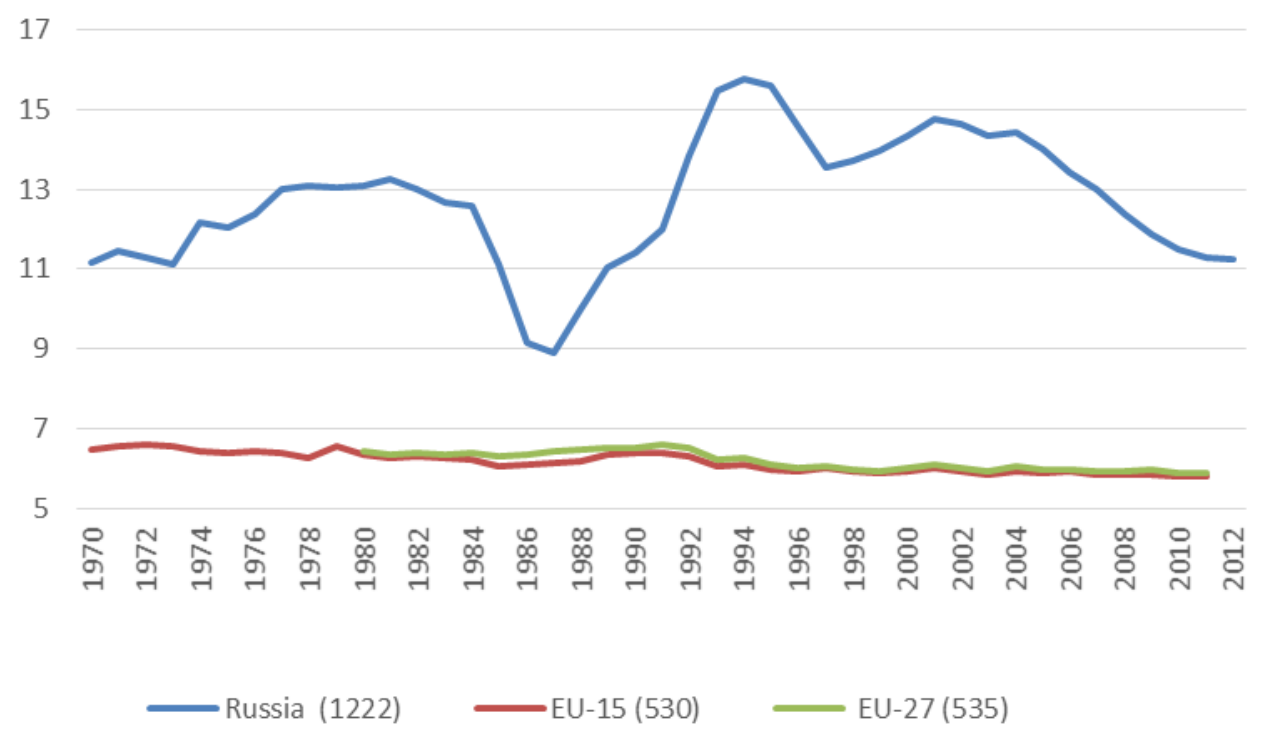

Figure 5. The share of external causes in the standardized mortality rate from all causes in Russia and EU countries, both sexes combined, 1970-2012, \%

Note: In parentheses - standardized death rate from all causes in 2010, per 100 thousand persons.

Source: Calculated from [WHO HFA 2014; RosBRiS 2014].

In countries with low mortality, external causes are usually ranked fourth among all causes of death - after cardiovascular diseases, neoplasms and respiratory diseases. In Russia, where the first epidemiologic revolution has not yet been completed, these four classes of causes of death are joined by digestive diseases, which sometimes even compete with respiratory diseases. But in Russia there is no competition between respiratory diseases and external causes of death; external causes are firmly in third place, and sometimes in second (Figure 6). Their contribution to the total number of deaths is comparable with the contribution of neoplasms and even sometimes surpassing it, which is not at all proper to countries with high life expectancy (Figure 7). 


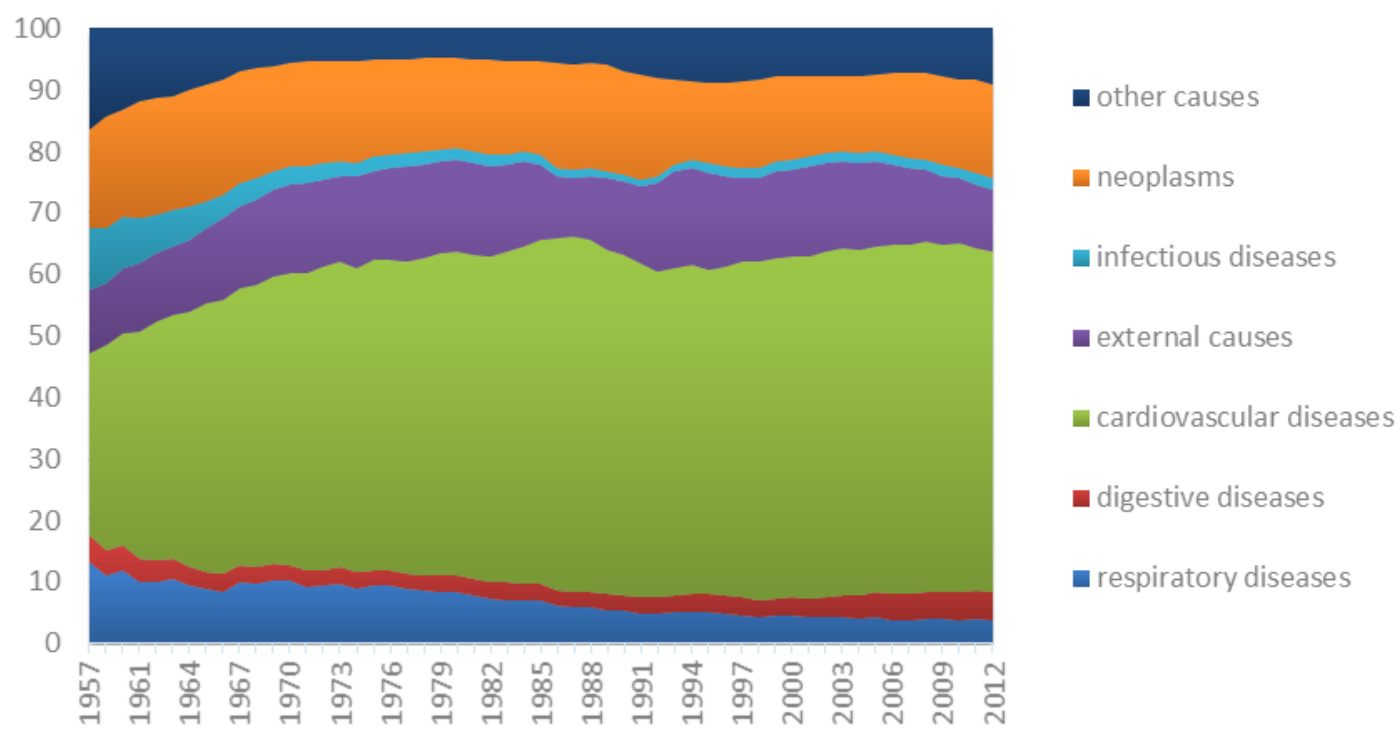

Figure 6. Distribution of the absolute numbers of deaths by major causes of death in Russia, 1956-2012, percent

Source: Calculated from [RosBRiS 2014].
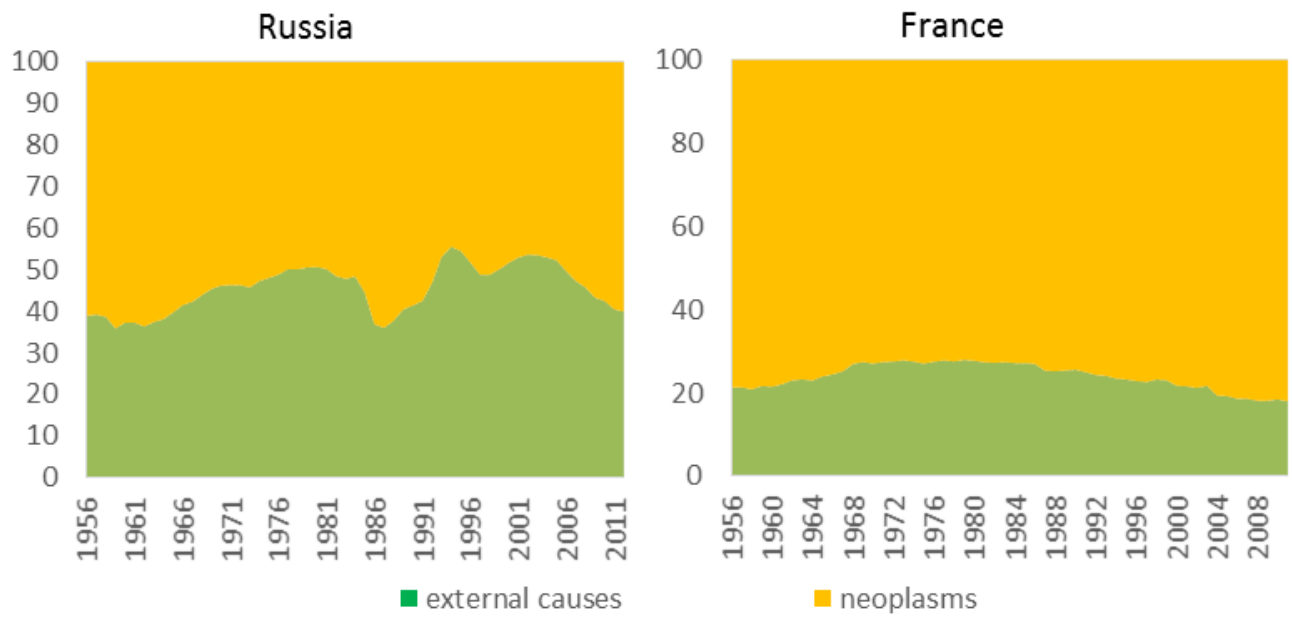

Figure 7. Ratio of the absolute number of deaths from external causes and neoplasms in Russia and France, 1956-2012, percent

Source: Calculated from [RosBRiS 2014; WHO MDB 2014].

In addition, external causes lead to increasing number of persons who have been injured and lost the ability to work, a number which is far greater than the number of deaths. This is evidenced by international experience. The 2006 Report on the WHO European region indicates that nearly 2,000 people are killed every day as a result of external causes, 60 thousand are taken to the hospital and 600 thousand are forced to seek emergency outpatient care [WHO 2006]. 


\section{MORTALITY FROM EXTERNAL CAUSES BY AGE AND SEX}

Despite the usual third or fourth places in the overall ranking of causes of deaths, mortality from external causes always ranks first among the causes of premature death because "children, youth and adults under the age of 45 are far more likely to die from injury than from illness" [Demograficheskaja modernizacija... 2006: 338]. Mortality from external causes in Russia demonstrates both differences by sex and age common to all countries, as well as particular country-specific features.

Although deaths from external causes everywhere hit males disproportionately, in Russia the gender gap is particularly large. The standardized female mortality rate from external causes in Russia is comparable to the male rate in Western Europe, while Russian male rate in Russia is 4-4.5 times higher than the female rate, as compared with 2.5 times in EU-15 (Figure 8).

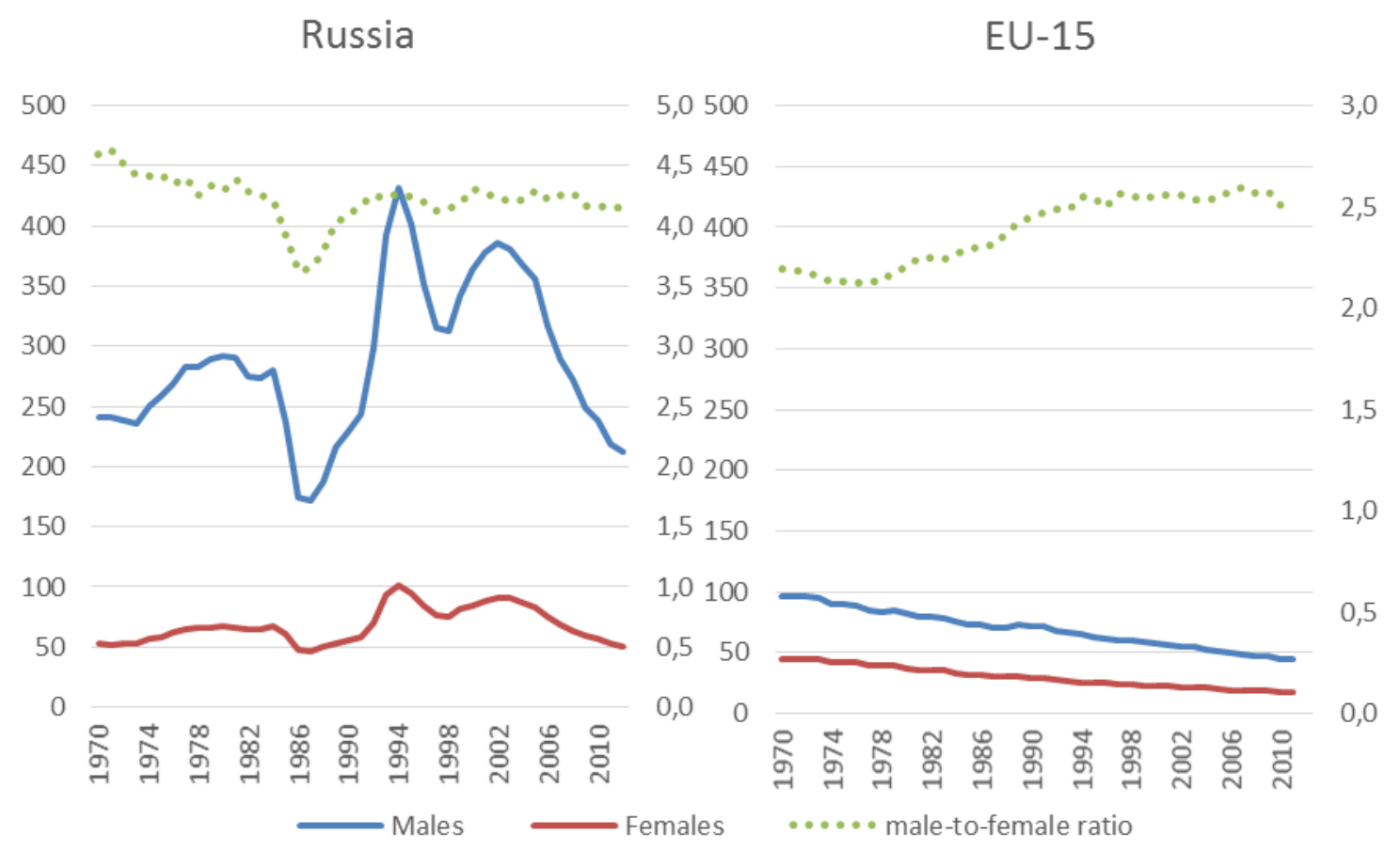

Figure 8. Standardized mortality rate from external causes by sex (left scale, per 100 thousand persons) and male-to-female ratio of rates (right scale, times-fold) in Russia and the EU-15, 1970-2012

Source: Calculated from [RosBRiS 2014; WHO HFA 2014].

Mortality from external causes is particularly noticeable in youth, when other causes of death are still weak. In 2012, the proportion of deaths due to external causes in all deaths among men and women is highest in age group 15-19 (Figure 9).

Although the contribution of external causes to overall mortality at different ages varies from year to year, the fluctuations are not very significant. For a long time, the largest contribution of external causes to overall male mortality was in age group 20-24. By this measure, age group 15-19 became the most affected since 1999. Among women the maximum contribution remains steadily in the 15-19 age group (Figure 10). 
The reduction of the proportion of deaths from external causes, after reaching its maximum rates among those aged 15-25, results from mortality from other causes, increasing with age rather than by age-related decreases in mortality from external causes. Concurrently, the level of mortality due to external causes in an age group may increase. This is precisely what is happening in Russia: age-specific death rates from external causes reach their highest values among men and women of working age (20 to 60), then fall and resume growing in older age (70 and older). This age pattern looks like an "injury mortality hump" on Figure 11. This hump was especially pronounced in 1993-1995 when indicators of mortality from external causes among middle-aged men were higher than, and among women were similar to mortality in the oldest age groups. The hump is characteristic not only of the whole category of external causes of death, but also of the most specific causes. It is particularly pronounced for traffic accidents, suicides, assaults and injuries with uncertain intentions, and is much more prominent among men.

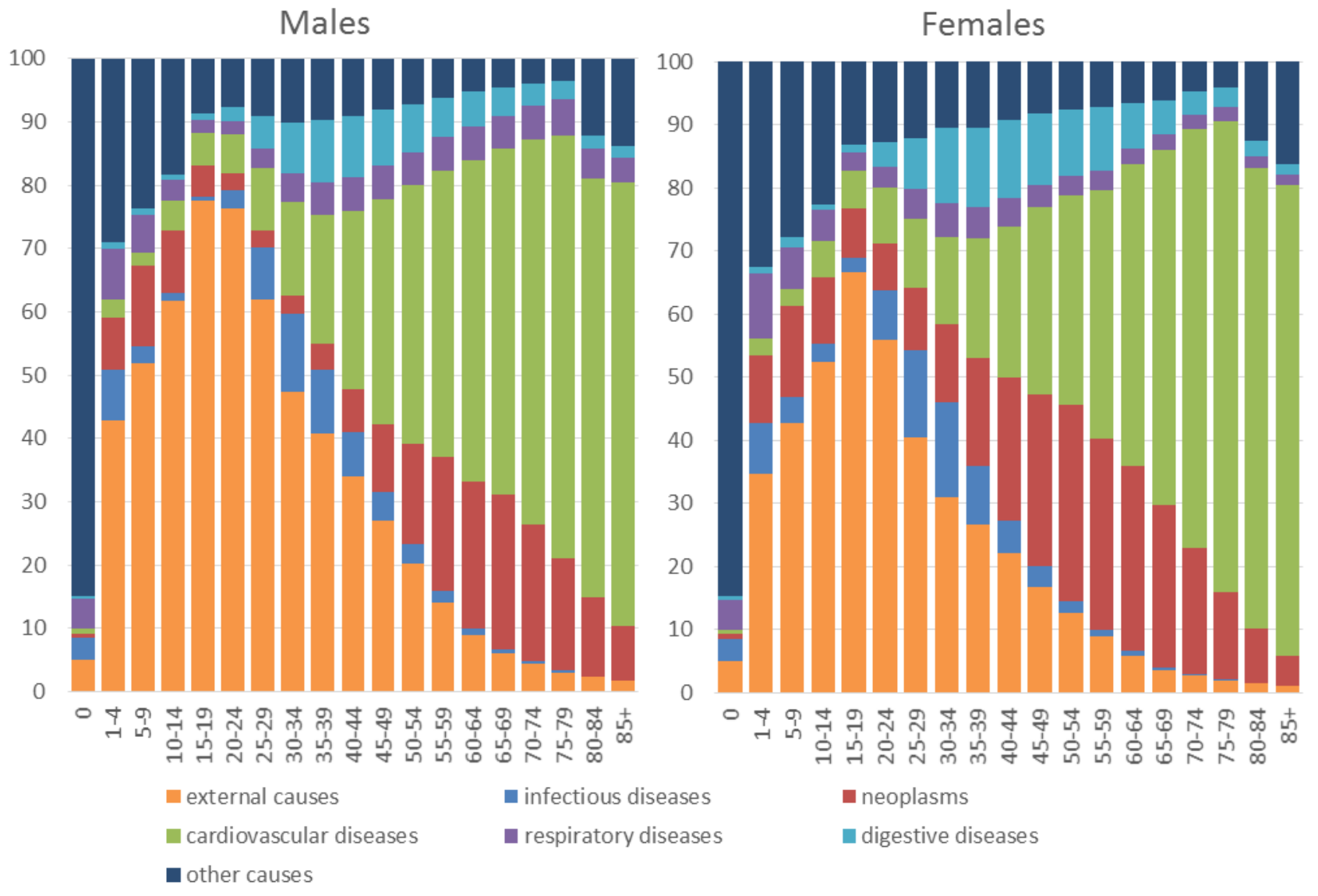

Figure 9. Distribution of deaths by main causes of death at different ages in Russia, 2012, men and women, percent

Source: Calculated from [RosBRiS 2014].

This age-related "injury mortality hump", observed in main working ages, in Russia leads to huge losses of life. In Western countries, mortality from external causes increases smoothly with age, particularly in countries with lower mortality (Figure 12). 
Males

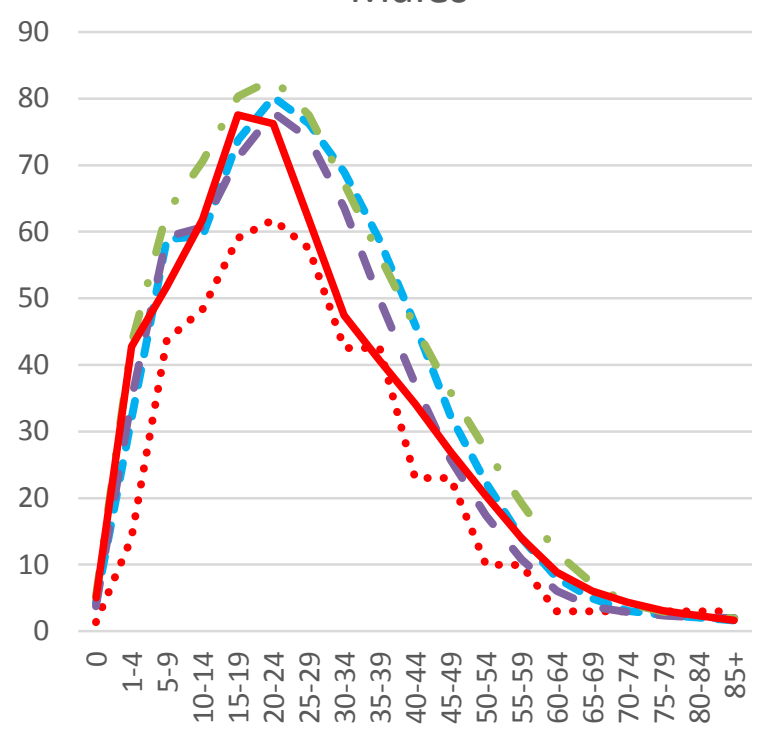

Females

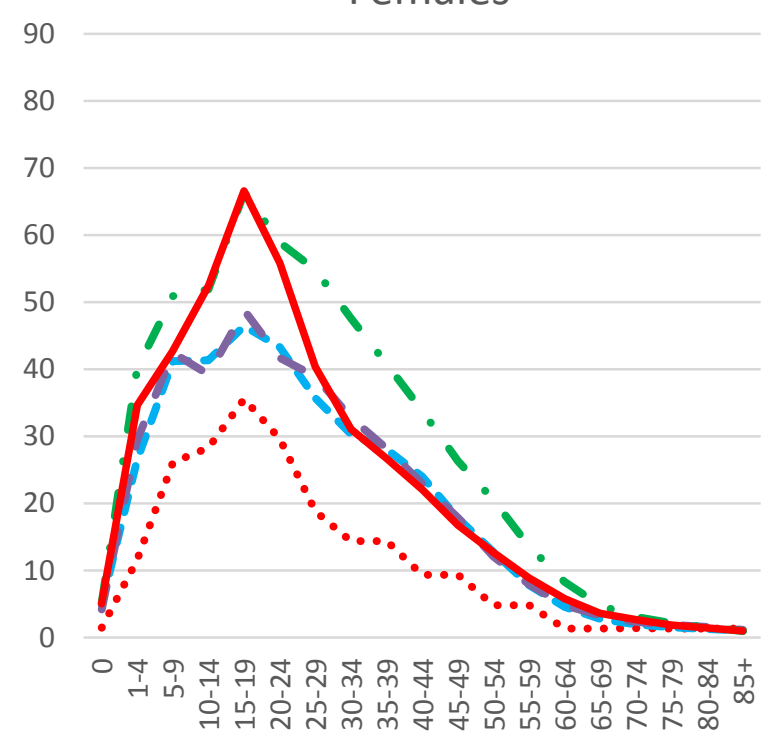

$$
1956 \quad-02012
$$

Figure 10. Percentage of deaths from external causes among all deaths, by age and sex, Russia, 1956, 1970, 1987, 1994 and 2012

Source: Calculated from [RosBRiS 2014].

\section{Males}

900

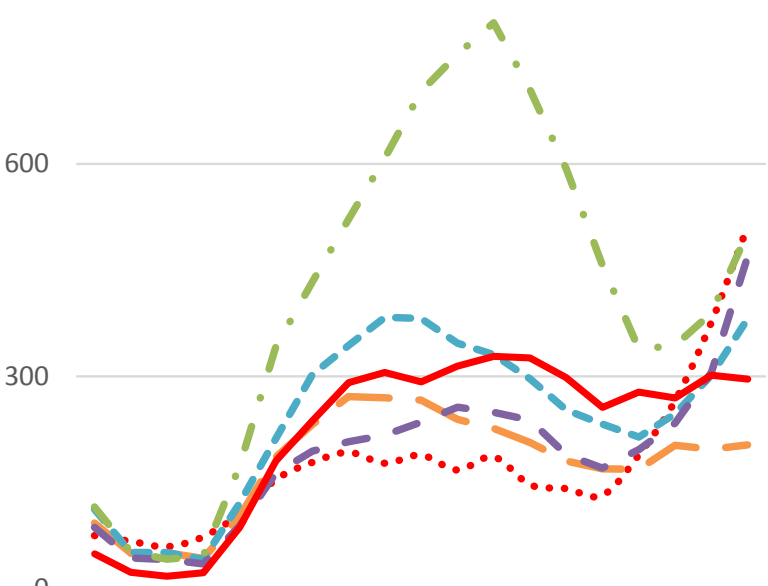

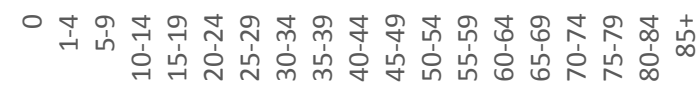

$$
1956-1965-01970
$$

Females

300

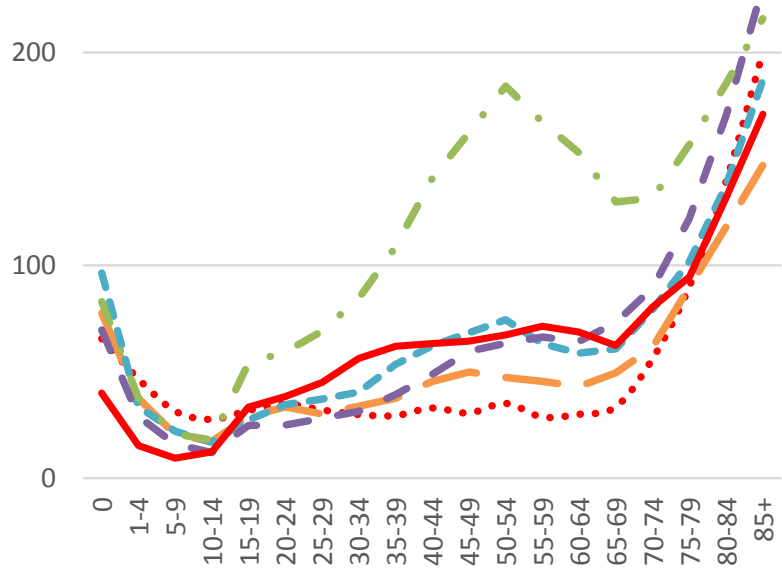

$-1987$

2012

Figure 11. Age-specific mortality rates from external causes in Russia, 1956, 1965, 1970, 1987, 1994 and 2012, men and women, per 100 thousand persons

Source: Calculated from [RosBRiS 2014]. 


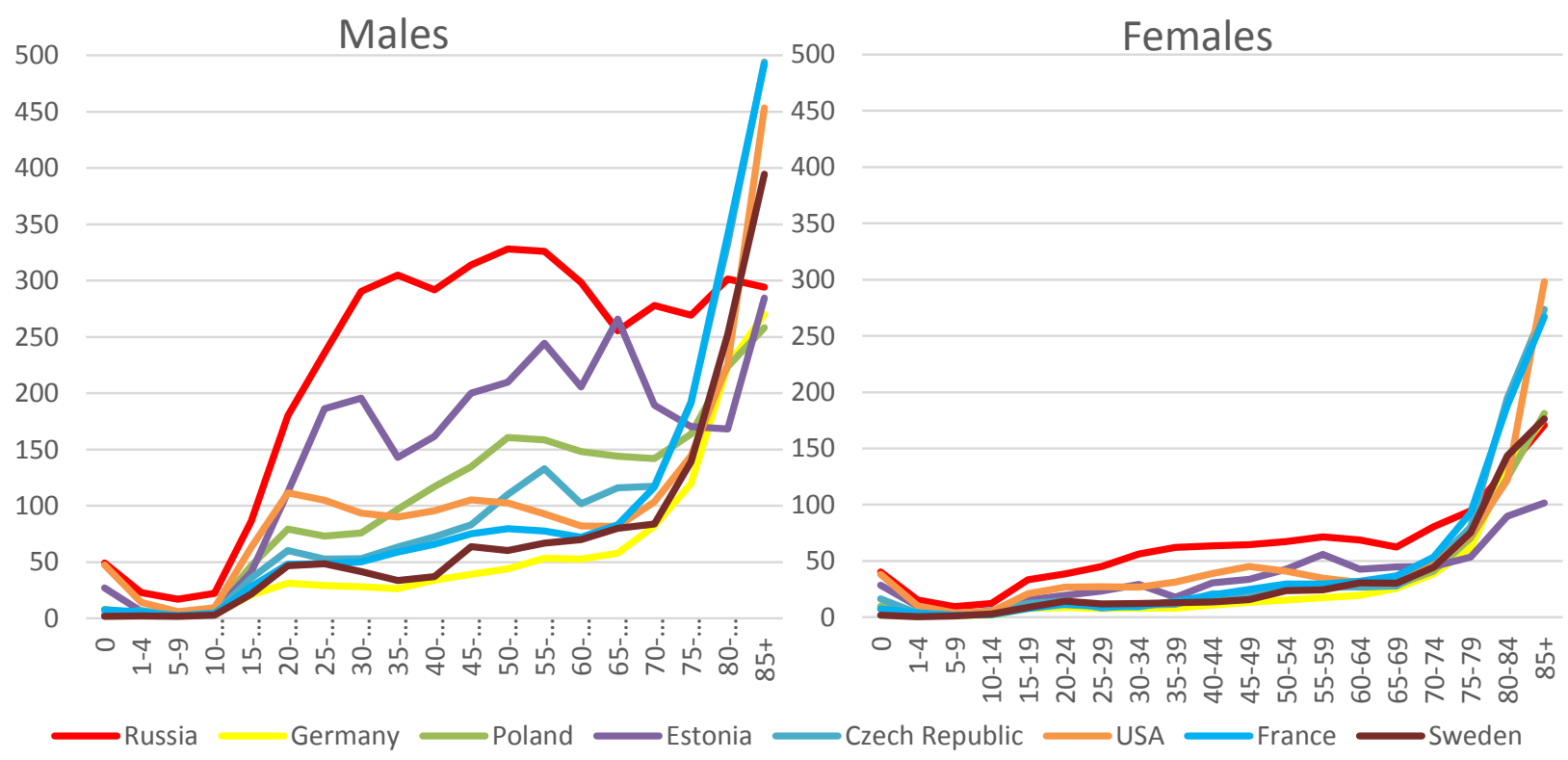

Figure 12. Age-specific death rates from external causes in Russia and some Western countries in 2010, per 100 thousand persons of the corresponding sex and age

Source: Calculated from [RosBRiS 2014; WHO MDB 2014].

\section{MORTALITY OF MEN AND WOMEN FROM MAIN GROUPS OF EXTERNAL CAUSES OF DEATH}

An exhaustive nomenclature of external causes of deaths would be voluminous. The international classification includes many relatively rare causes, such as a volley of fireworks, contact with a venomous snake or lizard and lightning strike. However, the vast majority of deaths from external causes result few groups of main causes, which the International Classification groups into rather groups. In the Tenth Revision of the International Classification of Diseases, the external causes of death include:

- transport accidents (V01-V99);

- intentional self-harm/suicide (X60-X84);

- assault/homicide (X85-Y09);

- injury with uncertain intentions (Y10-Y34);

- accidental poisoning and exposure to noxious substances (X40-X49), including accidental poisoning by and exposure to alcohol (X45);

- accidental falls (W00-W19);

- accidental drowning (W65-W74).

The list of the most important groups of external causes singled out for analysis may vary somewhat, but in general it is fairly stable. Causes of death not falling into one of these groups are 
collapsed into the group of "other accidents" 3 .

In the Russian structure of external causes of death, the greatest mortality in men is associated with factors such as self-harm (more than 1.8 million deaths in 1956-2012); transport accidents, including traffic accidents (1.4 million deaths); accidental alcohol poisoning (more than 1 million deaths); injuries with uncertain intentions (about 895 thousand deaths); and assaults (about 843 thousand deaths).

Among women, the largest number of deaths in 1956-2012 resulted from the same causes as for men, but with some differences in ranks. As among men, the first and the second ranks belong to self-harm (about 450 thousand deaths for the entire period) and transport accidents (about 426 thousand deaths); attacks (about 299 thousand deaths) came third, followed by accidental poisoning by alcohol (about 286 thousand deaths) and injuries with uncertain intentions (about 252 thousand deaths). Altogether, for both sexes these five causes accounted for about $65 \%$ of deaths from external causes in 1956-2012 (Figure 13).
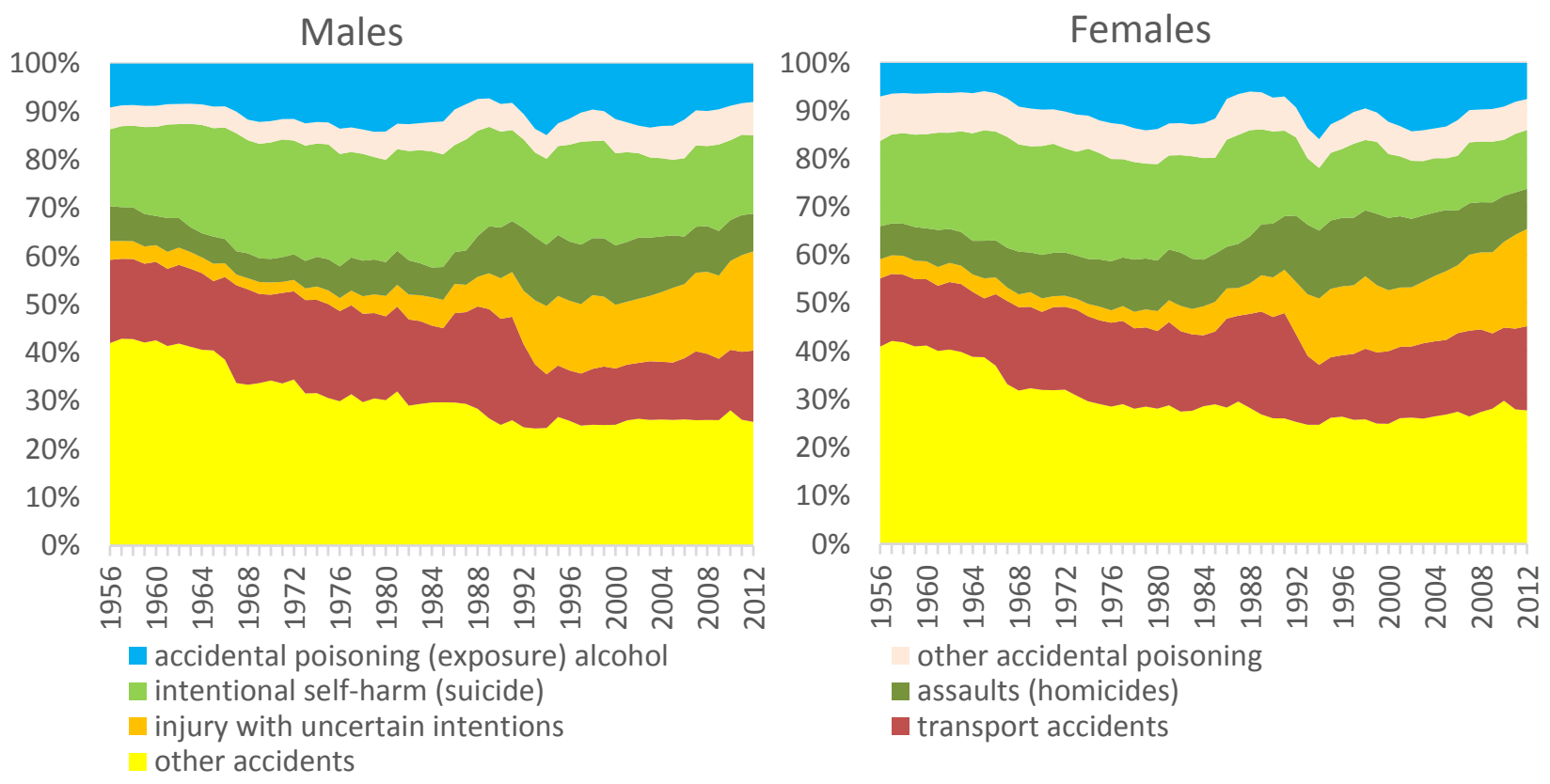

\section{Figure 13. Distribution of deaths from external causes by main groups of external causes of death in Russia, 1956-2012, \%}

Source: Calculated from [RosBRiS 2014].

Note: Accidental falls and accidental drowning are included in other accidents

The structure of external causes of death has not remained unchanged. Particularly revealing is the steady growth, in 1960-2012, of the share of injuries with uncertain intentions and the significant reduction of the proportion of deaths from accidental drowning and "other accidents", both and among men and women. Also, the share of deaths from suicide decreased among women. The shares of other causes changed less or even marginally. If they did change,

\footnotetext{
${ }^{3}$ For brevity, the following names of major causes of death are used in tables and figures below: transport accidents, intentional self-harm (suicide), assaults (homicides), accidental poisoning (exposure) alcohol, other accidental poisoning, injury with uncertain intentions, other accidents.
} 
they did not change particularly significantly - sometimes moving in different directions for the periods 1960-1990 and 1990-2012. Thus, the proportion of deaths from attacks, self-harm injuries and traffic accidents had increased between 1960 and 1990, but by 2012 shrank, as a result of which the ratio of shares over the last six decades has not changed much. For example, from 1960 to 1990 the proportion of male deaths from traffic accidents increased by nearly 6 percentage points, and then by 2012 it went down by more than 7 points (from 22 to 15\%); in other words, from 1960 to 2012 the proportion of deaths from this cause altogether shrank by only 1.5 percentage points (Table 1 and Figure 14).

Table 1. Distribution of deaths from external causes of death for men and women, 1960 , 1990 and 2012

\begin{tabular}{|c|c|c|c|c|c|c|}
\hline \multirow{2}{*}{ Cause of death } & \multicolumn{3}{|c|}{$\begin{array}{l}\text { Proportion of all deaths due to } \\
\text { external causes, percent }\end{array}$} & \multicolumn{3}{|c|}{$\begin{array}{c}\text { Increase (decrease) in share, } \\
\text { percentage points }\end{array}$} \\
\hline & 1960 & 1990 & 2012 & $\begin{array}{r}1960- \\
1990\end{array}$ & $\begin{array}{l}1990- \\
2012\end{array}$ & $\begin{array}{l}1960- \\
2012\end{array}$ \\
\hline \multicolumn{7}{|c|}{ Males } \\
\hline Accidental poisoning (exposure) alcohol & 8.7 & 8.4 & 8.0 & -0.4 & -0.4 & -0.8 \\
\hline Other accidental poisoning & 4.4 & 5.8 & 6.9 & 1.4 & 1.1 & 2.5 \\
\hline Accidental falls & 1.8 & 3.1 & 4.2 & 1.2 & 1.1 & 2.3 \\
\hline Accidental drowning & 14.7 & 6.4 & 4.6 & -8.3 & -1.8 & -10.1 \\
\hline Injury with uncertain intentions & 3.5 & 8.4 & 20.6 & 4.9 & 12.2 & 17.1 \\
\hline Assault (homicide) & 6.1 & 10.5 & 7.8 & 4.5 & -2.7 & 1.8 \\
\hline Intentional self-harm (suicide) & 18.5 & 19.9 & 16.3 & 1.4 & -3.6 & -2.2 \\
\hline $\begin{array}{l}\text { Transport accidents, including traffic } \\
\text { accidents }\end{array}$ & 16.3 & 22.0 & 14.8 & 5.7 & -7.2 & -1.5 \\
\hline Other accidents & 26.0 & 15.6 & 16.9 & -10.4 & 1.3 & -9.1 \\
\hline Total & 100.0 & 100.0 & 100.0 & & & \\
\hline \multicolumn{7}{|c|}{ Females } \\
\hline Accidental poisoning (exposure) alcohol & 6.4 & 7.2 & 7.5 & 0.8 & 0.3 & 1.1 \\
\hline Other accidental poisoning & 8.4 & 7.0 & 6.4 & -1.4 & -0.6 & -2.0 \\
\hline Accidental falls & 2.2 & 6.1 & 5.6 & 3.9 & -0.4 & 3.5 \\
\hline Accidental drowning & 11.9 & 3.8 & 2.8 & -8.2 & -0.9 & -9.1 \\
\hline Injury with uncertain intentions & 3.7 & 8.2 & 20.2 & 4.5 & 12.0 & 16.5 \\
\hline Assault (homicide) & 6.9 & 11.2 & 8.4 & 4.3 & -2.8 & 1.5 \\
\hline Intentional self-harm (suicide) & 19.6 & 19.2 & 12.2 & -0.4 & -6.9 & -7.4 \\
\hline $\begin{array}{l}\text { Transport accidents, including traffic } \\
\text { accidents }\end{array}$ & 13.8 & 21.1 & 17.5 & 7.3 & -3.5 & 3.7 \\
\hline Other accidents & 27.2 & 16.3 & 19.3 & -10.9 & 3.0 & -7.9 \\
\hline Total & 100.0 & 100.0 & 100.0 & & & \\
\hline
\end{tabular}

Source: Calculated from [RosBRiS 2014].

Note: Colored cells in a column indicate highest (red), second highest (yellow) and third highest (green) proportions.

The distribution of external causes of death in 2012 is presented in Figure 14.

By 2012, in comparison with 1990, the share of attacks in the total number of deaths from external causes declined from $11 \%$ to $8 \%$ for both sexes and the share of self-harm declined among men from $20 \%$ to $16 \%$ and among women from $19 \%$ to $12 \%$. These trends may be assessed as positive. However, the decrease of the proportions of deaths from assaults and self-harm injuries is accompanied by a growth in the share of injury with uncertain intentions. Most likely, a significant portion of violent deaths belongs to the latter category which requires collapsing the three categories together. Their total share does not show a positive dynamic: from 1960 to 2012 it increased from $28 \%$ to $45 \%$ for men and from $30 \%$ to $41 \%$ for women. 

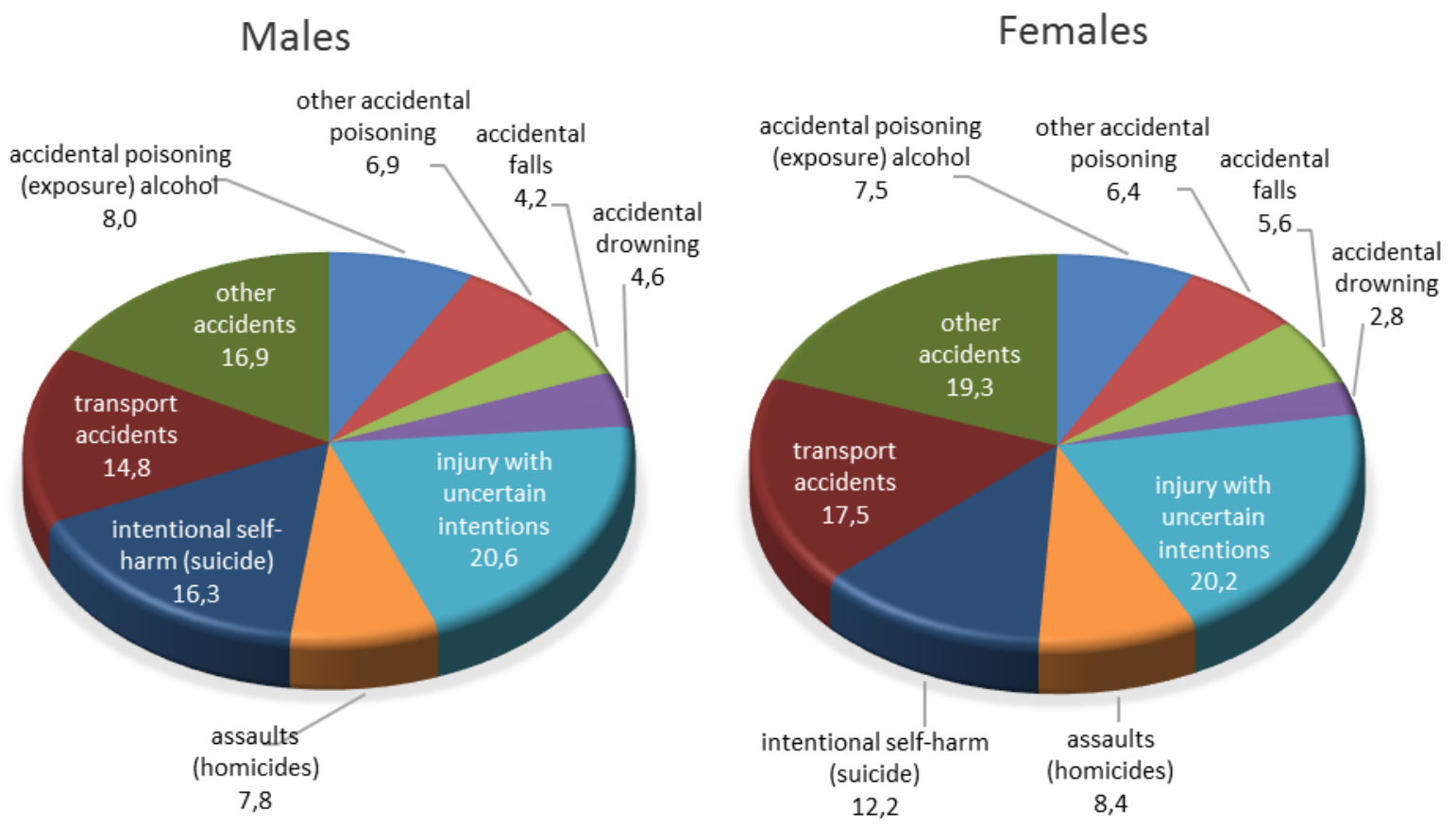

\section{Figure 14. Distribution of deaths from external causes of death in Russia by groups of causes in $2012, \%$}

Source: Calculated from [Rosstat 2013].

When comparing the structure of Russia's standardized mortality rate due to external causes, what is striking among both men and women is the high proportion of injuries with uncertain intentions, although by the total share of the three causes (injuries with uncertain intentions, attacks and suicide) Russia is close to such countries as Germany and Sweden, though of course with different levels of deaths from each of these causes.

Ignoring "other external causes", suicide becomes the strongest external cause of death in Western countries. In all countries presented in Figure 15, its share among men and women is larger than in Russia. In contrast, Russia is second only to the United States with respect to the share of external male deaths from homicide, and to Estonia with respect to female deaths from homicide.

In all countries, the largest contribution to the standardized rate of mortality from external causes is provided by the group "other external causes" (all causes, except those highlighted in Figure 15), although in Russia this contribution is smaller than in other countries.

The structure of "other external causes" varies greatly from country to country. For example, in the United States there is an unusually high proportion of accidental poisonings not linked to alcohol (arguably narcotic drugs); in Germany, Poland and Sweden accidental falls play an important role. Compared with other countries, Russia is characterized by the high proportion of deaths from exposure to smoke, fire and flames, as well as from accidental drowning (Figure 16). 


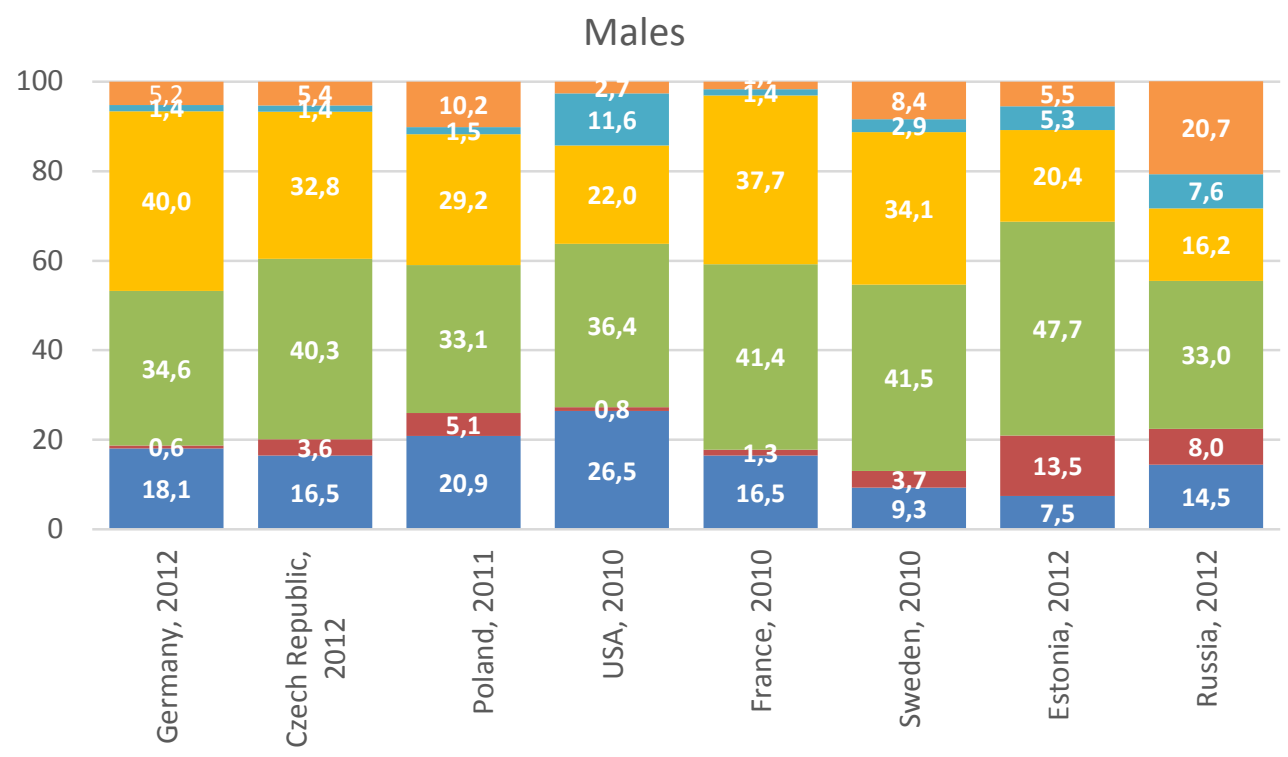

Females

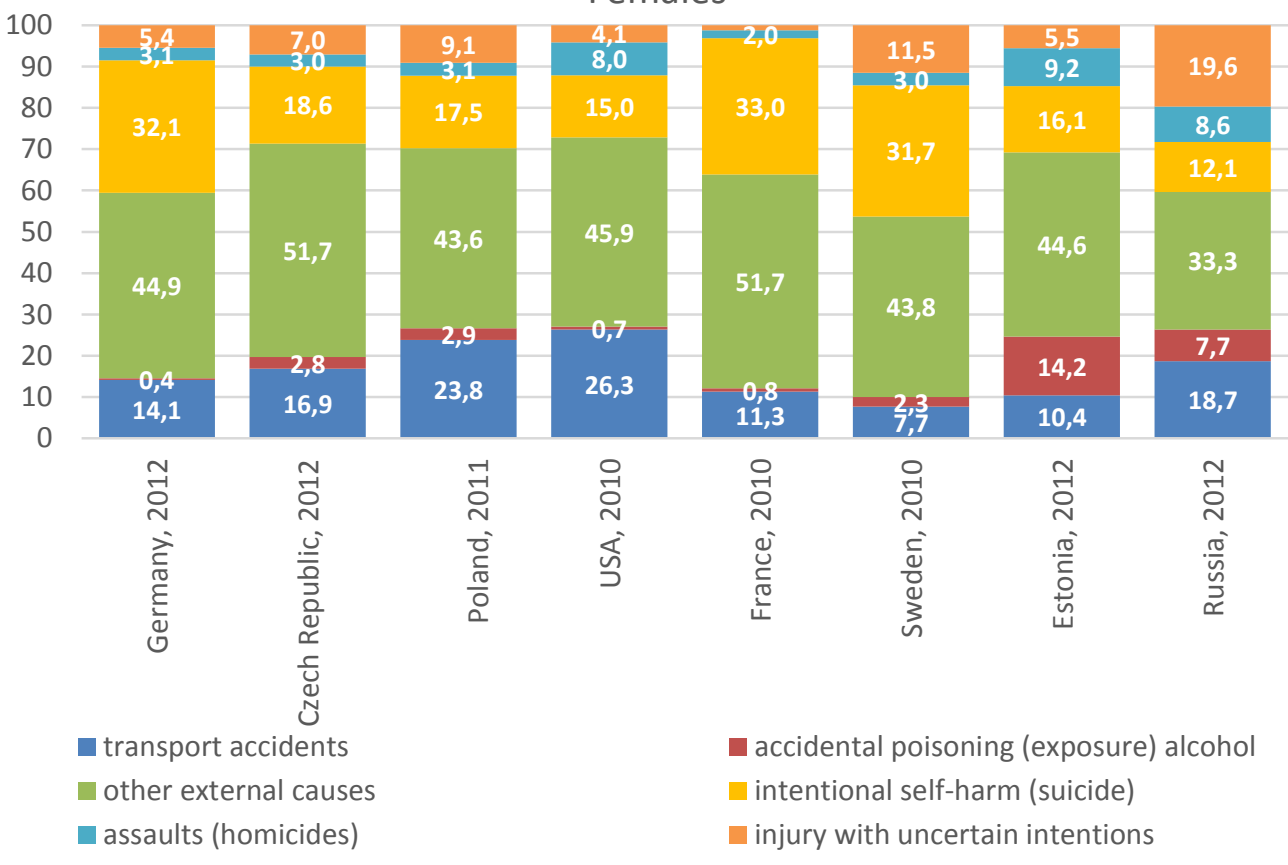

Figure 15. Structure of standardized mortality rates from external causes in Czech Republic, Estonia, Germany, France, Poland, Russia, Sweden and the United States, per 100 thousand males and females

Source: Calculated from [RosBRiS 2014; WHO MDB 2014].

Regardless of similarities or differences in the structure of mortality from external causes in Russia and other developed countries, these comparisons have only a limited value because Russia lags far behind these countries in terms of the overall level of mortality from external causes, as well as mortality from most constituent groups. As has been repeatedly noted, high mortality rates from virtually all external causes demonstrate that the Russians are poorly protected from carelessness, negligence or violence [Vishnevsky, Shkolnikov 1997]. Yet one also should not ignore structural differences, which often help with understanding the root causes of Russia's backwardness. 
Males

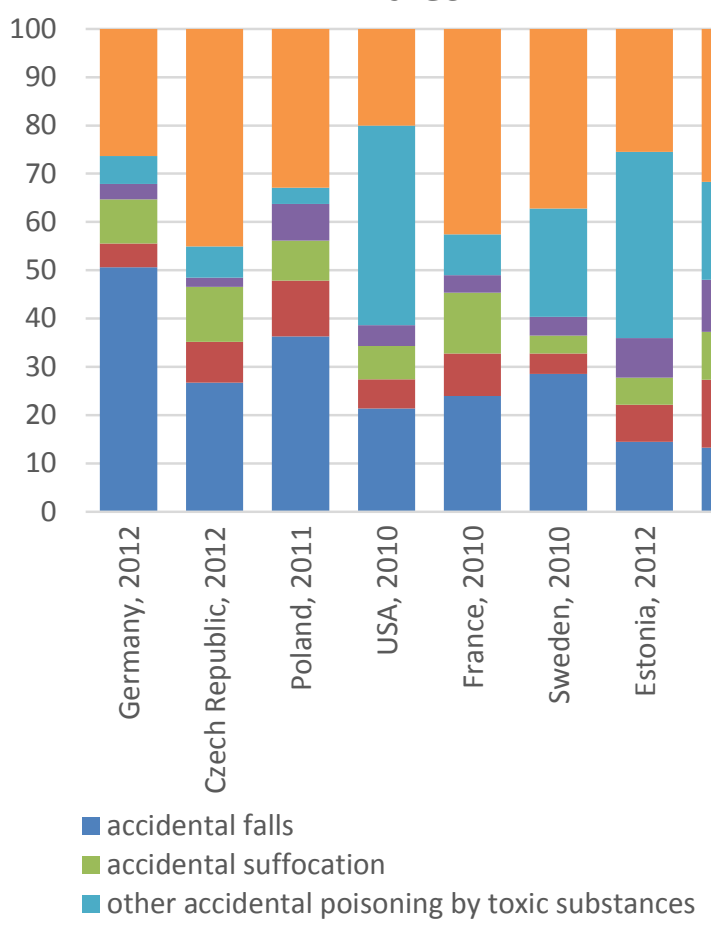

Females

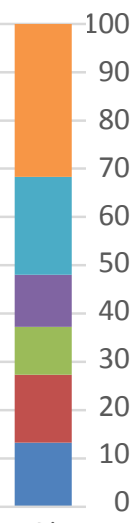

$\mid$

accidental drowning

- exposure to smoke, fire and flames

other accidents

Figure 16. Structure of standardized mortality rates from "other external causes" in Czech Republic, Estonia, Germany, France, Poland, Russia, Sweden and the United States, per 100 thousand persons of the corresponding sex

Source: Calculated from [RosBRiS 2014; WHO MDB 2014].

\section{AGE-RELATED FEATURES OF THE MAIN TYPES OF MORTALITY FROM EXTERNAL CAUSES}

It was demonstrated that overall mortality from external causes is characterized by age-related peculiarities, which makes such mortality ever different from mortality from other causes. There are also distinctive age-related features of mortality from each cause or group of external causes. A correct understanding of these features can arise from the analysis of $\boldsymbol{d}_{\boldsymbol{x} i}$ (where $\boldsymbol{d}$ is the number of deaths in the life table by causes of death, $x$ is the age and $i$ the cause of death.

These numbers provide the opportunity for a comparative analysis of their typical distributions for Russia and other countries. Tables 2 and 3 show the life table differences in mortality from varied groups of external causes by age group up to the age of 70 in Russia and, on average, in the EU-15. The difference $\left(d_{x i}^{R}-d_{x i}^{E U-15}\right)$, if positive, is interpreted as the age-specific and cause-specific excess number of deaths in Russia. 
Table 2. Excess male life table deaths from external causes up to age $70\left(d_{x i}^{R}-d_{x i}^{E U-15}\right)$ in Russia with respect to the EU-15, per 100 thousand male deaths, at all ages and from all causes, 2010

\begin{tabular}{|c|c|c|c|c|c|c|c|}
\hline Age & 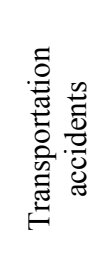 & 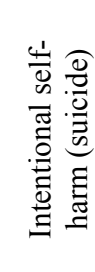 & 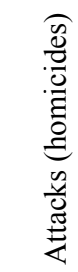 & 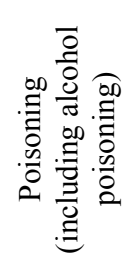 & 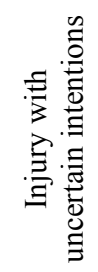 & 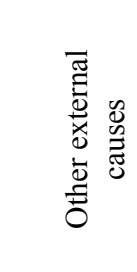 & 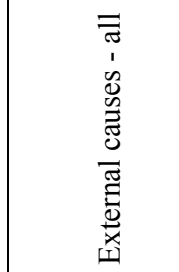 \\
\hline 0 & 3 & 0 & 9 & 2 & 11 & 71 & 97 \\
\hline $1-4$ & 17 & 0 & 6 & 26 & 11 & 95 & 154 \\
\hline $5-9$ & 41 & 2 & 6 & 11 & 7 & 93 & 160 \\
\hline $10-14$ & 35 & 28 & 10 & 7 & 13 & 78 & 171 \\
\hline $15-19$ & 92 & 147 & 85 & 83 & 86 & 192 & 685 \\
\hline $20-24$ & 224 & 321 & 214 & 288 & 219 & 337 & 1603 \\
\hline $25-29$ & 223 & 339 & 281 & 322 & 238 & 340 & 1744 \\
\hline $30-34$ & 210 & 321 & 304 & 299 & 236 & 382 & 1752 \\
\hline $35-39$ & 195 & 301 & 301 & 369 & 248 & 431 & 1845 \\
\hline $40-44$ & 181 & 304 & 290 & 443 & 279 & 493 & 1991 \\
\hline $45-49$ & 160 & 293 & 273 & 478 & 294 & 514 & 2013 \\
\hline $50-54$ & 128 & 255 & 232 & 423 & 288 & 481 & 1806 \\
\hline $55-59$ & 105 & 198 & 176 & 347 & 239 & 409 & 1474 \\
\hline $60-64$ & 80 & 115 & 113 & 247 & 169 & 270 & 994 \\
\hline $65-70$ & 39 & 101 & 61 & 129 & 86 & 118 & 534 \\
\hline Total & 1734 & 2726 & 2361 & 3476 & 2424 & 4303 & 17023 \\
\hline The numbe & ess de & & & & & $50-100$ & Less than 50 \\
\hline
\end{tabular}

Table 3. Excess female life table deaths from external causes up to age $70\left(d_{x i}^{R}-d_{x i}^{E U-15}\right)$ in Russia with respect to the EU-15, per 100 thousand female deaths, at all ages and from all causes, 2010

\begin{tabular}{|c|c|c|c|c|c|c|c|}
\hline Age & 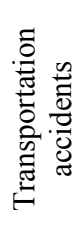 & 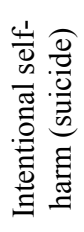 & 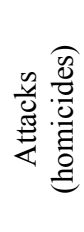 & 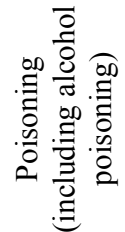 & 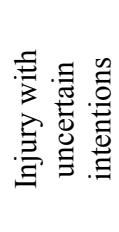 & 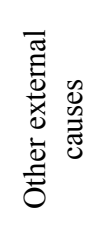 & 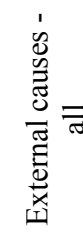 \\
\hline 0 & 2 & 0 & 11 & 3 & 9 & 58 & 83 \\
\hline $1-4$ & 14 & 0 & 6 & 19 & 8 & 62 & 109 \\
\hline $5-9$ & 20 & 0 & 5 & 8 & 5 & 35 & 72 \\
\hline $10-14$ & 19 & 7 & 9 & 3 & 5 & 26 & 70 \\
\hline $15-19$ & 56 & 32 & 38 & 31 & 24 & 35 & 216 \\
\hline $20-24$ & 58 & 30 & 60 & 51 & 39 & 47 & 285 \\
\hline $25-29$ & 57 & 34 & 72 & 45 & 40 & 53 & 300 \\
\hline $30-34$ & 48 & 32 & 78 & 56 & 45 & 61 & 320 \\
\hline $35-39$ & 53 & 28 & 75 & 82 & 51 & 73 & 362 \\
\hline $40-44$ & 49 & 28 & 80 & 106 & 58 & 87 & 408 \\
\hline $45-49$ & 49 & 27 & 82 & 132 & 66 & 109 & 466 \\
\hline $50-54$ & 53 & 27 & 78 & 145 & 75 & 126 & 504 \\
\hline $55-59$ & 51 & 23 & 74 & 157 & 75 & 128 & 506 \\
\hline $60-64$ & 45 & 23 & 56 & 106 & 56 & 94 & 380 \\
\hline $65-70$ & 49 & 31 & 46 & 76 & 40 & 69 & 312 \\
\hline Total & 622 & 322 & 772 & 1020 & 596 & 1061 & 4393 \\
\hline
\end{tabular}


The differences are especially large for men. Suppose mortality rates from age-sensitive external causes were similar in the Russian 2010 hypothetical cohort and in the EU-15. Then more than 17 thousand deaths from external causes among people under age 70 out of every 100 thousand actually registered male deaths would have been postponed beyond age 70 . The gaps increase with age (until age 50), and are greatest in the age range from 20 to 50 years. The largest contribution to this growth of excess deaths is provided by suicides in the age interval 20-45, attacks between the ages of 30 and 40, and especially poisoning and "other external causes" at all ages older than 20 .

The differences in mortality from external causes among women between Russia and EU15 are also noticeable, but are much smaller than among men: excess number of deaths from external causes under age 70 (about 4,400 per 100 thousand deaths) is approximately 4 times smaller. The differences increase with age up to age 60 and are particularly significant after age 40 , with poisonings making the largest contribution to mortality from external causes after age 40 and "other external causes" doing so after age 45.
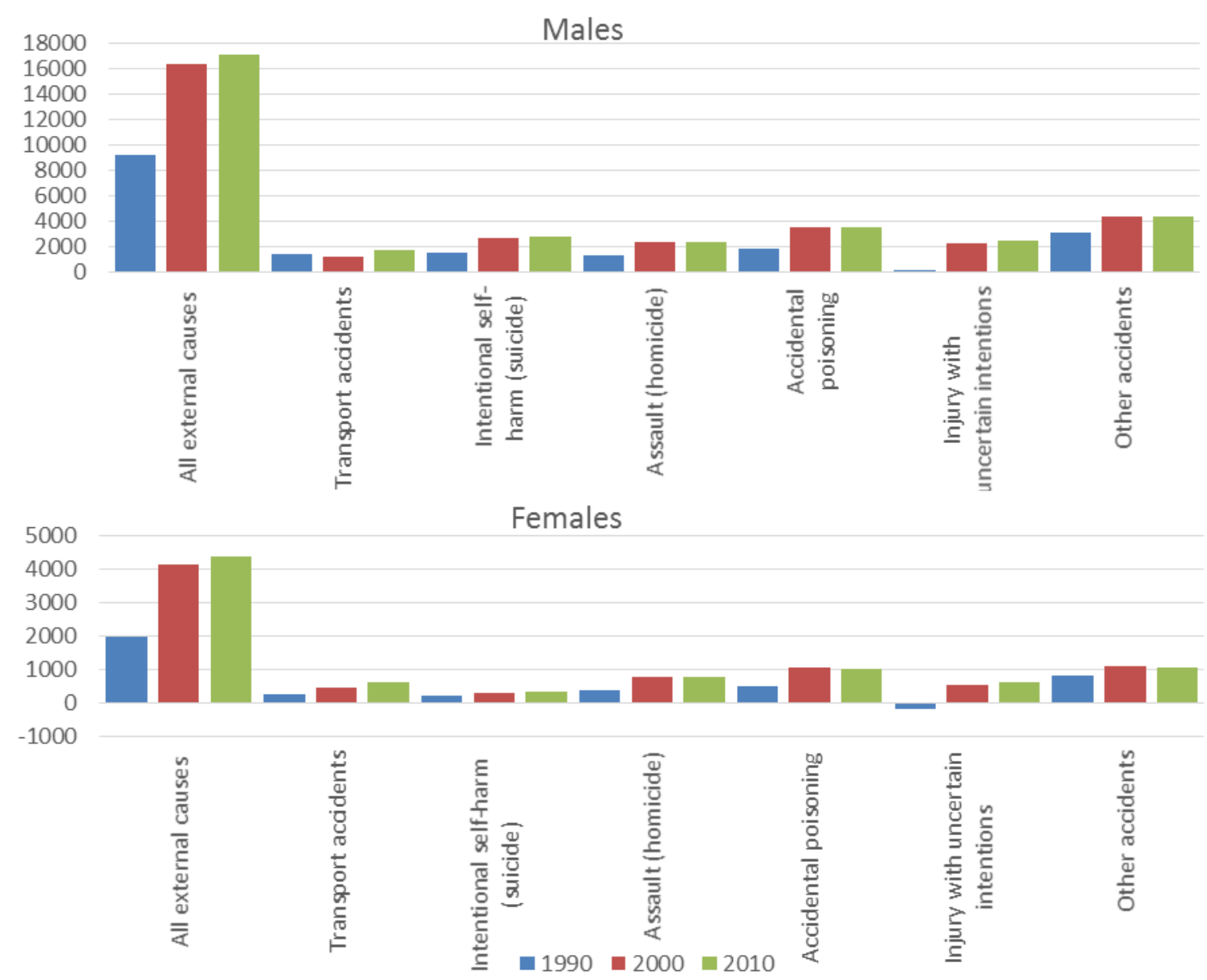

Figure 17. Excess life table deaths from external causes up to age $70\left(d_{x i}^{R} d_{x i}^{E U-15}\right)$ in Russia with respect to the EU-15, per 100 thousand deaths, from all causes, 1990, 2000 and 2010

Source: Calculated from [RosBRiS 2014; WHO MDB 2014].

Excess numbers of deaths were also calculated for other hypothetical cohorts. They are not presented here, but the graph in Figure 17, made with the estimates of the total number of excess 
deaths for 1990, 2000 and 2010, shows the stability of the hierarchy of causes of death that determine Russia/EU-15 differences. The largest contribution is provided by "other external causes", the second-largest is provided by poisonings (probably due to the high incidence of alcohol poisoning in Russia); suicides among men and homicides among women make the thirdlargest contribution. This hierarchy can be considered for determining policy priorities aimed at reducing mortality from external causes.

\section{MORTALITY FROM EXTERNAL CAUSES AND LIFE EXPECTANCY}

External causes constitute one of the two main causes of death determining the gap in life expectancy between Russia and the West.

The long-term dynamics of this indicator in Russia looks like waves. The period of 19561964 was characterized by increasing life expectancy. During the following 20 years life expectancy had fallen by 3.6 years for men and 0.8 years for women. Starting in 1985, in just 3-4 years of the anti-alcohol campaign, virtually all previous losses of male life expectancy were recovered (it increased by 3.3 years), and the growth of female life expectancy by 1.6 years overcompensated for its previous decline. The anti-alcohol campaign was short-lived and after its abandonment the decline of life expectancy resumed. In 1989-1994, life expectancy collapsed unprecedentedly having lost more than 7.5 years for men and 3.5 years for women. In 1995-1998, the indicator rose again by 3.8 years for men and 2.1 years for women, but this equaled only half of the preceding decline. The 1998 economic crisis led to a new reduction of life expectancy in 1999-2003, by 2.7 and 1.3 years for men and women, respectively. Finally, from 2004 to 2012 the indicator grew by 6.1 years for men and 4.2 years for women. In 2012, life expectancy was 64.6 years for men and 76 years for women. These values were only 2.7 and 5.4 years higher than those recorded in 1956, and roughly corresponded to the level of the mid-1960s for men and only slightly exceeded this level for women (Figure 18).

Males

70

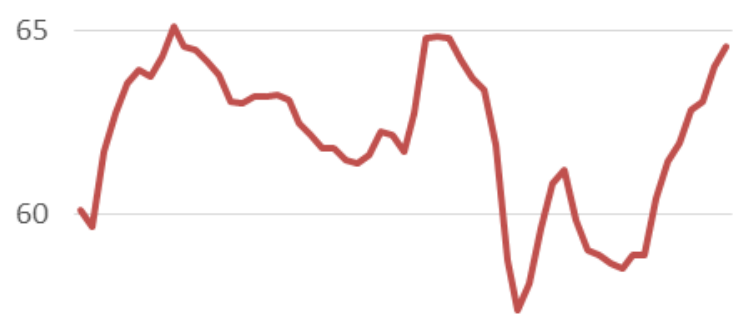

55

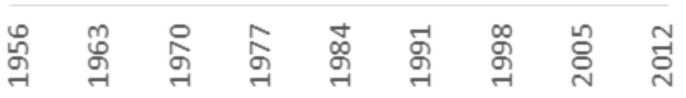

Females

80

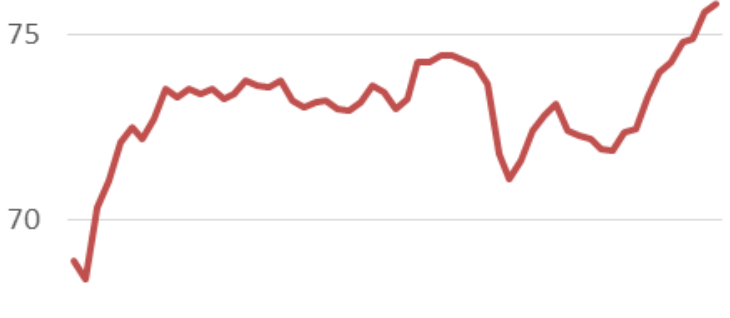

65

苛

Figure 18. Life expectancy of men and women in Russia, 1956-2012, years 
In other words, over the entire period from 1956 to 2012, despite all - sometimes sharp fluctuations, Russia has lived through more than half a century of stagnation in life expectancy. How, throughout this time, did the changes in mortality from external causes of death affect the level and dynamics of life expectancy?

As follows from Figure 19, the contribution of dynamics in external causes of death to changes in life expectancy was quite significant, especially among men.

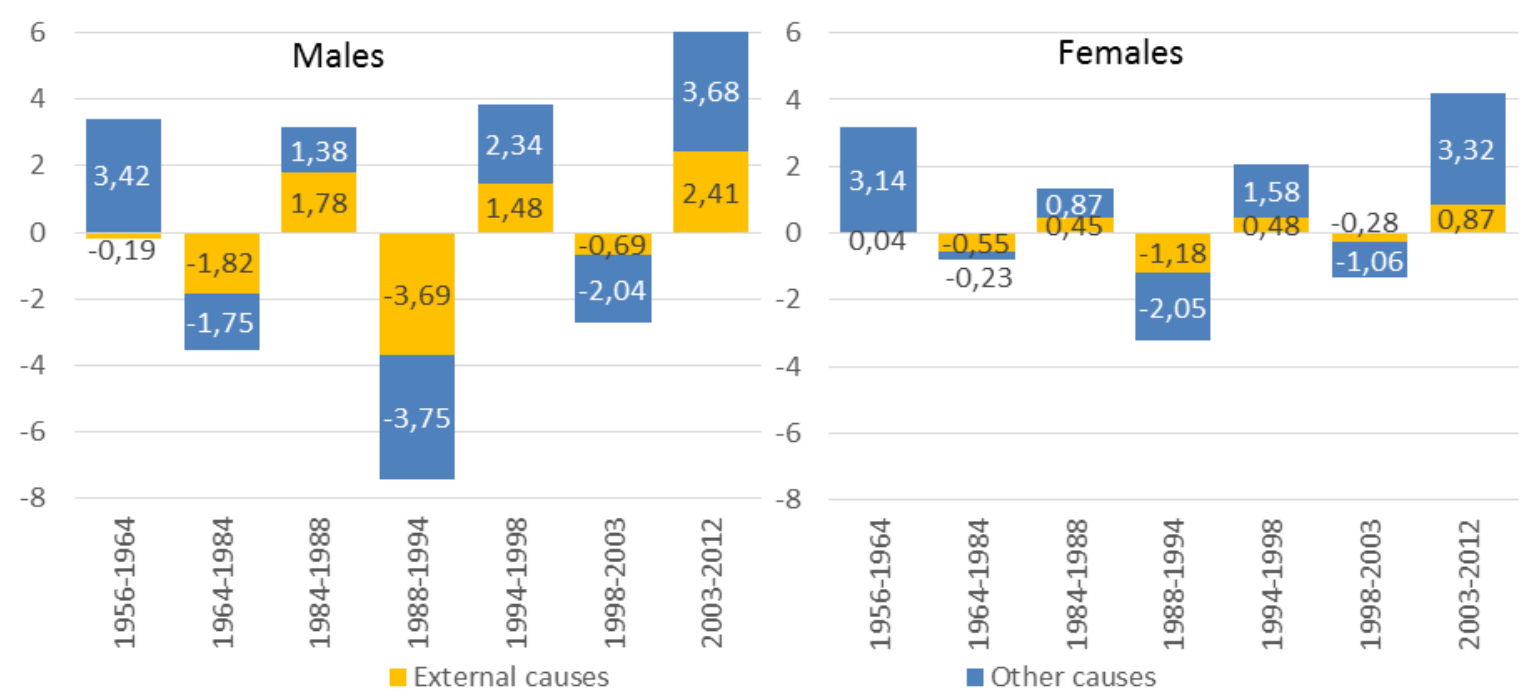

Figure 19. Contribution of changes in mortality from external causes to changes in life expectancy at birth, 1956-2012, years

Source: Calculated from [RosBRiS 2014].

Both at the stages of growth and of decline of life expectancy, this contribution was markedly age-specific. In the younger and older age groups, it was relatively small, and at younger ages it was more often positive. The decisive impact on the ups and downs of life expectancy resulted from the changes in mortality from external causes among 15-64-year-olds. (Figure 20). As the positive and negative impacts of fluctuations in mortality from external causes on life expectancy were virtually symmetrical, the overall effect over the period of 57 years was insignificant, even though these fluctuations eventually reduced male life expectancy by one year. 


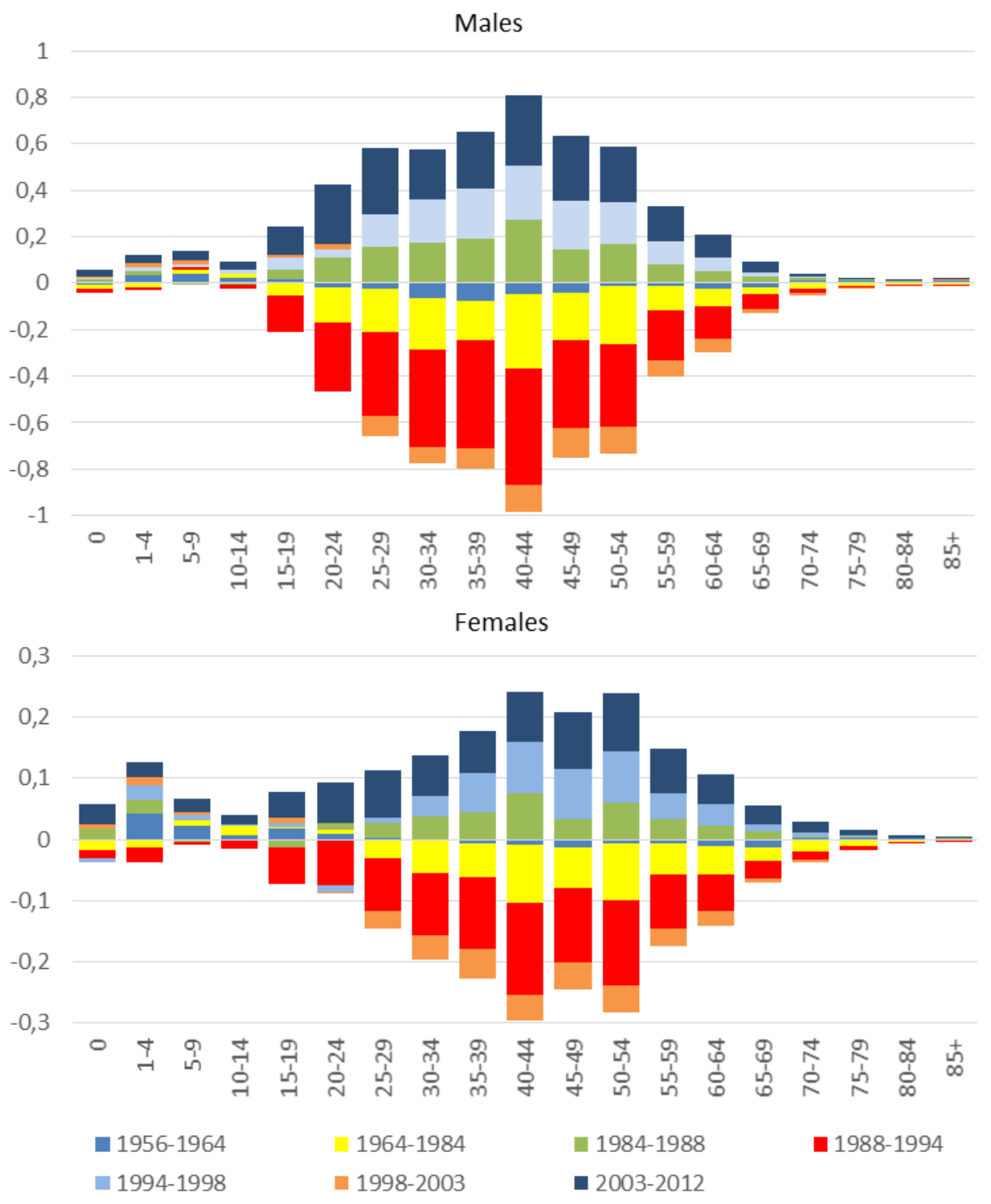

Figure 20. Contribution of changes in mortality from external causes to changes in life expectancy of men and women, by age groups and periods, 1956-2012, years

Source: Calculated from [RosBRiS 2014].

Of particular interest is the impact of changes in mortality from each group of external causes between the ages of 15 and 64 on life expectancy during 1956-2012. If we take as a starting point life expectancy at birth in Russia in 1956 (then a relatively low 62 years for men and 70 years for women), then the growth or reduction of this indicator due to changes in mortality from each class of causes between the ages of 15 and 65 makes it possible to judge which classes of causes of death were the most important in terms of the formation of the life expectancy of Russians and its dynamics during the period under review.

As follows from Figure 21, throughout this period the reduction in mortality from infectious diseases made the major positive contribution to the increase in life expectancy for both men and women, although the magnitude of this contribution varied from period to period. 
Among women, a consistently positive contribution to the increase of life expectancy since 1956 was provided by a mortality decrease from "other diseases" and tumors. In men, the effect of these two types of improvement was less pronounced and less stable. Beginning in the 1990s, the negative contribution to life expectancy of the rise in adult mortality from diseases of the digestive system begins to look anomalous.

But the most striking adverse impact on the dynamics of life expectancy was produced by the increases in mortality from cardiovascular diseases and, in particular, from external causes.

By the end of the 1970s, increased mortality from external causes between the ages of 15 and 64 lowered life expectancy at birth by 2.3 years for men and 0.5 years for women from the 1956 level. By 1994, the decline had reached its maximum values of 4.1 years for men and 1.2 years for women. The fluctuations of curves on Figure 21 that reflect the impact of diseases of the circulatory system on life expectancy closely mirror the fluctuations of curves for external causes of death, yet the losses from the latter were smaller. Since the mid-1980s, for the third time both lines have been moving towards the positive half-plane, but so far only diseases of the circulatory system, and only among women, briefly went through this transition (in 1986-1991, as well as starting from 2011). The curve of the accumulated contribution of external causes of death to the change in life expectancy is the only one that never left the negative half-plane. By 2012, mortality from external causes in the age interval 15-64, which still remains higher than it had been in 1956, has led to losses of life expectancy of about 1.2 years for men and 0.4 years for women.

Increased mortality (between the ages of 15 and 64) from diseases of the circulatory system provided the largest contribution to that decline (-1.2 years, or $48 \%$ of the total). Increased mortality from external causes also lead to a very substantial change ( -1 year, or $38 \%$ of the total decline in life expectancy). Diseases of the digestive system ranked third among the culprits (-0.4 years, or $15 \%)$. Due to the summary effect of all causes of death, male life expectancy at birth would have declined by 2.6 years in 1956-2012. Mortality from all other causes receded and provided the collective positive input into life expectancy of the order of 1.1 years, so the net effect was the decline in male life expectancy by 1.5 years (Figure 22).

The dynamics of external causes of death and digestive diseases negatively affected life expectancy of women ( -0.4 years and -0.3 years, respectively), providing $54 \%$ and $46 \%$ of the overall negative impact). However, the positive contribution of the decrease in mortality from other causes added 1.4 years to life expectancy resulting into the net increase of 0.7 years over the period 1956-2012.

Life expectancy of men and women is now higher than it was in 1956, but this is primarily due (especially for men) to reduced child mortality. For both sexes under the age of 15, mortality between 1956 and 2012 decreased from all major causes of death, including external ones (among men the contribution to the reduction in mortality from external causes was 0.3 years of the total increase of 4.2 years, or $8 \%$ of life expectancy at the age of 15 , and among women 0.2 years of the total of 4.1 , or $5 \%$ ). 

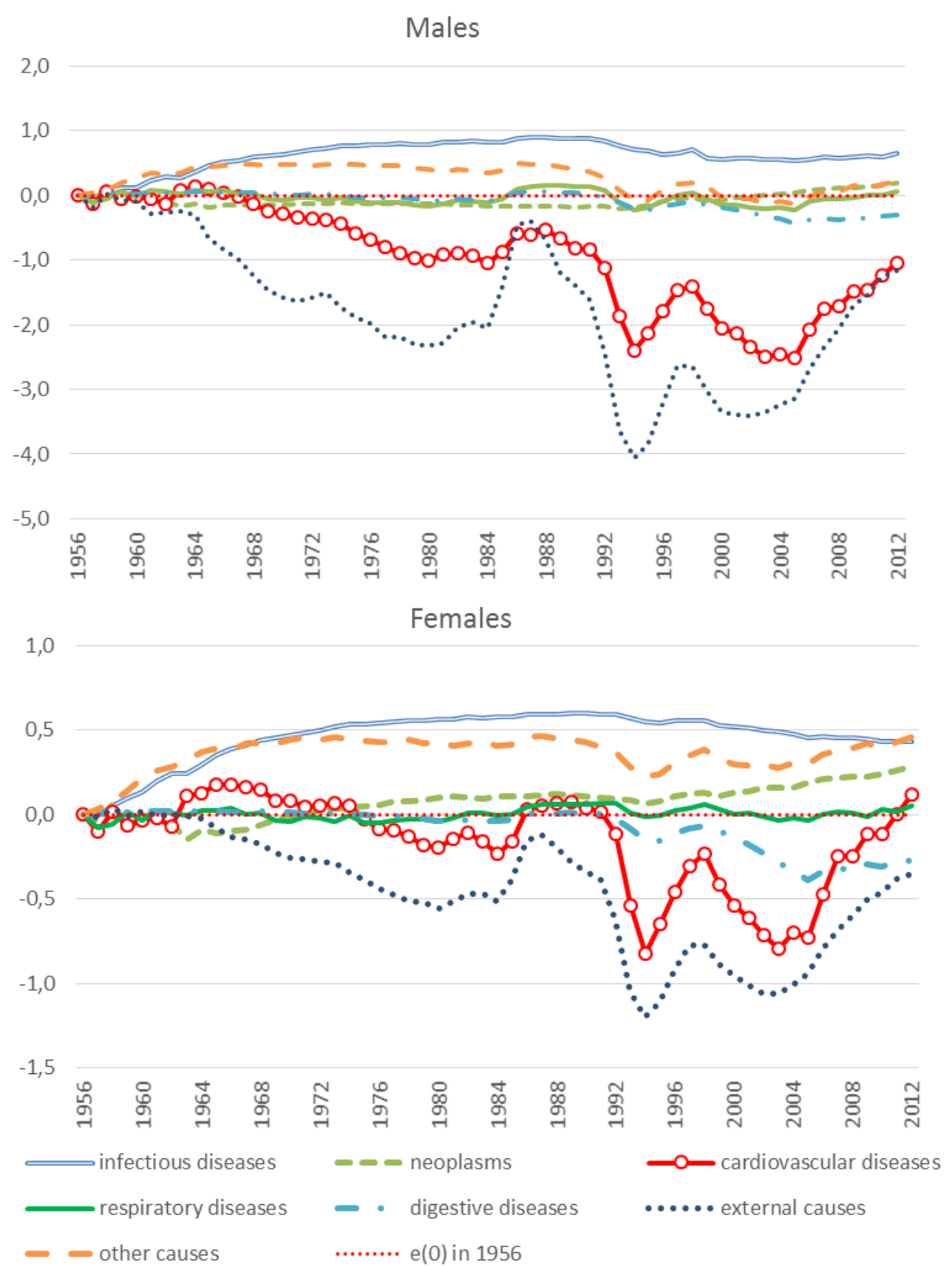

Figure 21. The gain or decline in life expectancy due to changes in mortality from main classes of causes of death between the ages of 15 and 64, 1956-2012, years

Source: Calculated from [RosBRiS 2014].

Note: 1956 is a reference year

The increase in life expectancy of older people - those 65 and older - is observed only among women, and it is small. The reduction of mortality from external causes is too small to provide a discernable positive contribution to life expectancy. 


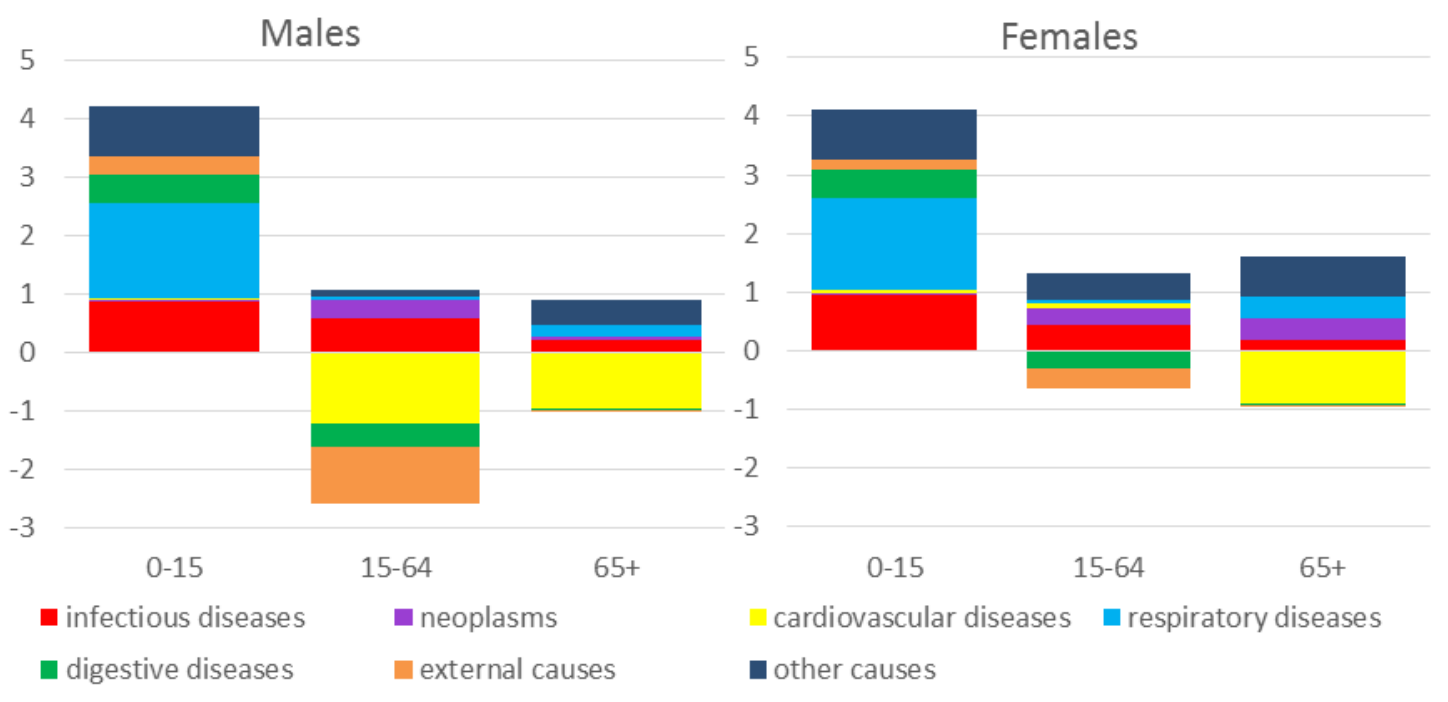

Figure 22. Decomposition of changes in life expectancy due to changes in mortality from major age groups and classes of causes of death, 1956-2012, years

Source: Calculated from [RosBRiS 2014].

Thus, the increase in mortality from external causes of death in the 15-64 age group group for both sexes had a significant negative impact on the changes in life expectancy. Among men of this age group this impact was almost comparable to the negative impact of the increases in mortality from cardiovascular diseases, and among women it competed with that of the increase in deaths from diseases of the digestive system. Concurrently, the changes in mortality from diseases of the circulatory system period provided, in the long run, a positive contribution to the change in life expectancy of women.

In 2012, Russia's life expectancy at birth of both sexes combined has finally surpassed 70 years, but life expectancy for men, especially at the age of 15, was still lower than in the mid1960s or during the anti-alcohol campaign. Life expectancy of 15-year-old women surpassed the maximum reached during the period $1960-1988$ by only 0.5 years. The population of Russia lived, in the last decade, not so much through an increase in life expectancy than through recuperation of the losses incurred previously. The country still lags behind the developed countries. Taking into account the unstable nature of mortality from external causes, it is difficult to foresee future trends.

\section{REFERENCES}

Bogoyavlensky D. [Богоявленский Д.Д.] (2001). Smertnost' ot vneshnih prichin v Rossii [Mortality from external causes in Russia] // Demoscope Weekly. № 29-30. URL: http://www.demoscope.ru/weekly/029/tema01.php (accessed: 28.10.14).

Demograficheskaja modernizacija Rossii 1900-2000 [Demographic modernization in Russia 1900-2000] (2006) / A.G. Vishnevsky, ed. M.: Novoe izdatelstvo.

Meslé F., Shkolnikov, V. Hertrich V. Hertrich et J. Vallin (1996). Tendances récentes de la mortalité par cause en Russie 1965-1994. Paris, INED. URL:

http://demoscope.ru/weekly/knigi/shkol/shkol.html (accessed: 28.10.2014) 
Meslé F., J. Vallin, V. Hertrich, E. Andreev, V. Shkolnikov (2003). Causes of death in Russia: assessing trends since the 1950s // European Population Conference "Population of Central and Eastern Europe. Challenges and Opportunities"/ Irena E. Kotowska, Janina Józwiak, eds. Warsaw: Statistical Publishing Establishment: 389-414. URL: http://demoscope.ru/weekly/knigi/epc.php (data accessed: 09.10.2014).

National Center for Health Statistics of USA (NCHS) (2014). Injury and Violence Prevention and Control. URL: www.cdc.gov/injury (accessed: 09.10.2014).

Rosstat (2013). Demographic Yearbook of Russia, 2013 article. Sat. M.: Rosstat. URL: http://www.gks.ru/bgd/regl/B13_16/Main.htm (accessed: 15.10.2014).

RosBRiS (Russian database of births and deaths). Center for Population Research at the New Economic School (2014). URL: http://www.demogr.nes.ru/index.php/ru/demogr_indicat/data_description (accessed: 09.10.2014).

Vishnevsky A., V. Shkolnikov [Вишневский А.Г., В.М. Школьников] (1997). Smertnost' v Rossii: glavnyye gruppy riska i prioritety deystviya [Mortality in Russia: main risk groups and priorities of action]. Nauchnyye doklady Moskovskogo Tsentra Karnegi [Scientific reports of the Carnegie Moscow Center]. Vyp.19: 83.

WHO (2006). Injuries and violence in Europe. What is the importance of the problem and what can be done. Summary. WHO: 26. URL: http://www.euro.who.int/_data/assets/pdf_file/0008/98405/E87321R.pdf (accessed: 10.09.2014).

WHO DMDB (World Health Organization European Detailed Mortality Database) (2014). URL: http://www.euro.who.int/en/data-and-evidence/databases/european-detailed-mortalitydatabase-dmdb2 (accessed: 10.09.2014).

WHO HFA (World Health Organization European Health for all database) (2014). URL: http: //data.euro.who.int/hfadb/ (accessed: 10.09.2014).

WHO MDB (World Health Organization Mortality DataBase) (2014). URL: http://www.who.int/healthinfo/statistics/mortality_rawdata/en/index.html (accessed: 09.10.2014). 